\title{
Pricing and Safety Investment Decisions in Food Supply Chains with Government Subsidy
}

\author{
Yanan Yu $\mathbb{D}$, Yong He $\mathbb{B}$, and Melissza Salling $(\mathbb{D}$ \\ School of Economics and Management, Southeast University, Nanjing 210096, China \\ Correspondence should be addressed to Yong He; hy@seu.edu.cn
}

Received 30 December 2020; Revised 31 March 2021; Accepted 9 April 2021; Published 28 April 2021

Academic Editor: Yan Zhang

Copyright (C) 2021 Yanan Yu et al. This is an open access article distributed under the Creative Commons Attribution License, which permits unrestricted use, distribution, and reproduction in any medium, provided the original work is properly cited.

\begin{abstract}
As the demand for safe food has been rapidly increasing these years, more and more stakeholders are dedicated to the safety of the food in the supply chain of this sector. To expand the market share of safe food, governments of some countries also provide subsidies to encourage food processors to invest in better food safety efforts. This paper establishes a three-stage game model between the government and a twostage food supply chain that consists of one supplier and one processor, where the government subsidizes processors to invest in food safety efforts; furthermore, this paper determines the optimal wholesale price, marginal profit, food safety investment, and government subsidies. This paper analyzes the effects of the government subsidies and risk aversion of the food processor and introduces the mode of order quantity-based payment and demand-based payment; moreover, it also analyzes the impacts of subsidies and different payment methods on demands. The results show that suppliers can increase the market share of products by adopting the demand-based payment, but this method does not always benefit the members of the supply chain. As the processor is more risk-averse, the optimal subsidy is higher, encouraging the processor to invest in more efforts. Finally, the supplier's profit increases with the processor's risk aversion indicator.
\end{abstract}

\section{Introduction}

Consumers across the world are increasingly adopting healthy lifestyles and thus changing their eating habits which leads to the rapid growth of the global health and wellness of the food market. The intensification and industrialization of agriculture and animal production create both opportunities and challenges of food safety in order to meet the increasing demand for food. Since the customer demand for food is an important role of formulating various agricultural and food policies, governments should make food safety a public health priority, as they play a pivotal essence in developing policies and regulatory frameworks, as well as establishing and implementing effective food safety systems. Governments in Canada subsidize food processors to reopen or upgrade facilities of processing domestic food or to modernize and automate plants that have closed or are operating at less than full capacity. India subsidizes unorganized food processing sector to provide infrastructure and services supporting the growth of new food businesses. Recently, literature on government subsidy in a supply chain is quite rich. Different forms of subsidies are also compared [1-3].
International Organization for Standardization (ISO) defines quality as the totality of features and characteristics of a product that bears its ability to satisfy stated or implied needs. It is analyzed by experts that safety is the most important factor or component of quality as lack of safety can lead to serious consequences like the serious injury or even death of a person (see https://www.fssaifoodlicense.com/ different-food-safety-food-quality). Qin et al. indicated that quality is the term based on some subjective and objective measurements of the food product including measures of sensory, nutrition, safety, wholesomeness, or any other attribute of the product [4]. Although ultra-processed foods tend to taste good, they usually contain ingredients that could be harmful if consumed in excess, such as saturated fats, added sugar, and salt (see https://www.medicalnewstoday. com/articles/318630\#what-is-processed-food). It was found that eating more than 4 servings of processed food daily may result in an increased risk of all-cause mortality (see https:// www.bmj.com/content/365/bmj.11949). Customers therefore hold different attitudes towards processed food, making the food supply chain members uncertain about the customers' 
perceived quality. Big data, combined with reliable information on food consumption, makes it possible for risk assessors to assess consumers (see https://www.efsa.europa.eu/ en/topics/topic/data). In this context, we assume that the initial customers' perceived quality is observable and fluctuates within a certain range, and this paper studies the situation where the food processor is risk-averse and considers risk attitude towards pricing and safety investment decisions.

This paper focuses on studying the effects of different payment methods and government subsidies on increasing customer demands for safe food. The decisions about selling price, wholesale price, safety investment, order quantity, and government subsidies are optimized to maximize the profits of channel members and social welfare. Different from previous studies, this paper expands three aspects as follows. Firstly, this paper studies the impacts of food processing subsidies on the food safety investment, as well as pricing and market share. Secondly, the heterogeneity of the costumers' quality perception leads to demand volatility. This paper highlights the impact of food processor's risk aversion on the decision making in a food supply chain. Thirdly, we compare two payment methods, one is the order quantitybased payment in which the food processor pays the supplier regarding the order quantity and undertakes all the deterioration costs, and the other is the demand-based payment in which the supplier shares parts of the deterioration costs. The further parts of this paper are organized as follows. Section 2 summarizes relevant literature. Section 3 describes the issue, formulates the model, and solves the issue. Section 4 analyzes the influence of parameters on optimal decisions and compares different cases under different payment methods by using the numerical simulation. Finally, findings and future research directions are discussed in Section 5.

\section{Relevant Literature}

Our research mainly focuses on food pricing and food safety. An apparent gap exists between perceptions of the costumers and between the facts to innovative processed meat products [5]. However, food processors can affect perceived quality by adopting safety measures. Lee et al. analyzed the understanding of Chinese customers' perceptions of nonthermal processing technologies and ways to mitigate negative perceptions [6]. Asseldonk et al. found that understanding growers' preferences regarding interventions to improve the microbiological safety of their production could help to design more effective strategies for the adoption of such food safety measures by growers [7]. Regulations and specifications on processing technology in the food industry could improve product quality and customer trust [8] and could affect the expected price in the spot markets [9]. Food safety investment is confirmed to improve food quality. Hoffmann et al. reviewed the empirical research of the safety of produced and consumed food; furthermore, they suggested that midsize and larger firms should be in co-regulation and should also reward farmers and firms for investing in food safety [10]. Zheng and Fan investigated how product freshness and risk preference affect the profits of the fresh agricultural products supply chain. They found that increasing investment of science and technology on fresh agricultural products can greatly improve the quality and safety of fresh products [11]. The decisions about food pricing and quality investment are also studied. Lin studied an optimal replenishment model with dynamic pricing and quality investment for perishable products to maximize the total profit per unit time [12]. Moon et al. investigated freshness coordination decisions under the consideration of consumers' freshness preferences [13]. Wang and Zhao determined the optimal investment levels of the cold chain construction, advertisement, and optimal pricing in a fresh food supply chain. They found that collaborative cold chain investment and collaborative pricing are superior strategies for the supply chain [14].

Similar to the research above, we also investigate the operations management problems for food pricing and food safety. Differently, we focus on investigating the optimal safety improvement efforts and the corresponding pricing strategies of the risk-averse food processor which faces uncertain perceived quality. Moreover, the government subsidy on food processing is integrated into the decision framework, the feasible region and amount of government subsidy are provided, and the effects of deterioration coefficient and the food processor's risk aversion indicator on the decision of subsidy are studied, which are novel in the food quality and food safety literature.

Our research is also related to the cooperation in food supply chain. The relations between the suppliers and the degree of integration of the activities along with the supply chain are studied [15]. The benefits of cooperation are also investigated. Mesa and Gomez found that a more stable relationship between suppliers and retailers in the perishable produce market will render the supply firm more cooperative, competitive, and profitable. The retail channel and market diversification have a positive effect on the relationship between cooperation and the performance of the supplier [16]. Labrecque et al. found that in order to prosper in an uncertain marketplace, it needs to reduce its production costs, increase product awareness in the domestic market, and promote cooperation among industry members [17]. Rucabado and Cuellar suggested that small producers that are interested in short food supply chains must be aware of the special importance of social linkages and of the need to take care of them as well as of the need of establishing synergies and cooperation with other producers and stakeholders [18]. Cooperation of the perspective of operations management is also studied. Chen and Dan analyzed the cooperation based on a benefit-sharing contract used within a two-level supply chain with random production and demand [19]. Huang et al. established a Stackelberg game model for a three-level food supply chain consisting of one retailer, one vendor, and one supplier with production disruption. They found that the retailer's preservation investment can benefit all the supply chain members [20]. He et al. designed the green innovation effort level parameters and discussed the incentive strategy of cost-sharing led by manufacturers. They found that manufacturers need to 
stimulate their green innovation efforts by sharing the cost of suppliers, and the cost-sharing contract can optimize the overall income of the food supply chain [21]. Wang and Zhao found that collaborative cold chain investment and collaborative pricing are superior strategies for the supply chain [14].

We study the method where the processor pays the supplier based on the actual demand, and the processor and the supplier undertake the deterioration loss together, which contributes to the market expansion of the product; in addition, we also compare two payment methods, order quantity-based payment and demand-based method, respectively. Furthermore, the joint effects of government subsidies and different payment methods on the market expansion, as well as the profits of the supply chain members, are also examined.

Big data has been employed to manage food quality or food safety problems in the supply chain. Singh et al. proposed a big-data analytics-based approach that considers social media (Twitter) data to identify supply chain management issues in food industries [22]. Qian et al. presented novel technologies, including batch mixing optimization with AI, quality forecasting with big data, and credible traceability with blockchain, in the context of improving traceability performance in food processing [23]. Kappelman and Sinha considered a dynamic food supply chain with multiple process steps where the decisions at each step include supplier selection and settings for their process parameters. They proposed an integrated approach that uses big data mining techniques to study the effect of these decisions on the quality of the final product and determined the state transition matrix [24]. In terms of customers' food quality perception, Mishra et al. identified factors influencing consumer's beef purchasing decisions and established interrelationships between these factors by using big data supplemented with ISM and fuzzy MICMAC analysis [25]. Nardi et al. reviewed 128 empirical studies and found that trust, knowledge, subjective characteristics, and sociodemographic characteristics are critical driving factors of food safety risk perception (FSRP). They also analyzed the negative effects of FSRP on consumers' willingness to pay. The effects of a supply chain member's food safety risks on other members' decisions are also investigated [26]. Hou et al. surveyed Chinese fruit farmers to study the effect of farmers' risk attitude and contract arrangements on contract implementation by using a probit model [27]. Schoenherr et al. developed a framework for ensuring food safety through relationship networks. They found that consumers' stress can positively affect a firm's learning orientation and risk aversion, which in turn affected informal and formal relationship networks [28].

Big data makes the customer's perceived quality be observable. Therefore, this paper assumes that the customer's perceived quality is fixed and fluctuates within a certain range. Then, this paper studies the situation where the food processor is risk-averse and considers risk attitude towards pricing, safety investment, and subsidy decisions.

Another stream of our research is the risk-averse individual's optimal decision by using the mean-variance (mv) method. Chiu et al. considered the coordination problem with a risk-neutral manufacturer that supplies to multiple heterogeneous retailers [29]. Cui et al. studied a risk-averse retailer's optimal decision of introducing her store brand product by using the mean-variance formulation [30]. Chiu et al. considered a luxury fashion firm serving a conspicuous market consisting of two groups of customers who influence each other and investigated the optimal customer portfolios and budget allocation problem using the mean-variance framework [31]. Zhao and Zhu explored a risk-averse marketing strategy for a remanufacturer and a retailer in a remanufacturing supply chain [32]. The decision of the government is also incorporated into the model. Deng et al. studied a Stackelberg game where the government, as the leader, designs the subsidy policy to reach the electric vehicle adoption target and the risk-averse electric vehicle manufacturer, as the follower, determines the production quantity and selling price. They found that the manufacturer's profit does not necessarily decrease with the risk aversion because the production subsidy improves profit effectively [33]. Chiu and Choi [34], Choi et al. [35], and Wen and Siqin [36] provided comprehensive reviews of the applications of the mv theory in supply chains.

Different from the extant literature, this study incorporates food safety investment into the food supply chain. We consider the uncertain and endogenous customers' perceived quality which can be improved by the food processor's food safety investment and government subsidy together. We study the joint effects of two payment methods and government subsidies on market expansion and the profit of supply chain members, and we further investigate the effects of the food processor's risk aversion and deterioration coefficient on decisions.

\section{The Model}

Fresh food may suffer deterioration loss during the transportation and sales process due to the perishable features; similar to $\mathrm{He}$ et al. [37], we use $f$ to represent the deterioration ratio of the food and $1-f$ to represent the surviving ratio of the food. Cai et al. characterized the optimal decisions of a fresh product supply chain where the freshness-keeping effort of the distributor impacts the quality and the quantity of the product delivered to the market [38]. In this article, the distributor is responsible for sales and takes on all deterioration costs. Yu and Xiao investigated the pricing and service level decisions of a fresh agri-products supply chain consisting of one supplier, one retailer, and one third-party logistics [39]. In their model, the retailer is responsible for sales, while the supplier takes on all deterioration costs. We compare two payment methods, one is the order quantity-based payment in which the food processor pays the supplier based on the order quantity and undertakes all the deterioration costs, and the other is the demand-based payment in which the supplier shares parts of the deterioration costs. We study the effects of government subsidies and different payment methods on the increasing demands for safe food. 
When neglecting the government subsidy for processing the product, this paper considers a supply chain consisting of a leading food processor and a supplier. Due to the fact that the share of small-scale food producers in terms of all food producers in countries in Africa, Asia, and Latin America ranges from 40 to 85 per cent (see https://sdgs.un.org/goals/goal2), this paper assumes that the food processor dominates the supplier. We study the pricing and order decisions, and we compare the optimal decisions under order quantity-based payment and demand-based payment, respectively. Furthermore, we study the situation of a food processor who invests in the safety efforts to improve customers' belief in the quality of products and the situation of a government who dominates the whole supply chain providing the food processor subsidies to increase customer demands. We study the pricing, safety investment, order, and subsidy decisions and compare two payment methods.

3.1. Notations. The notations shown in Table 1 are used to model our problem.

\subsection{Assumptions}

(1) The government is the leader in the three-stage game, and it firstly determines the food processing subsidy. Secondly, the food processor determines the marginal profit and processing investment decisions, and finally, the supplier determines the wholesale price.

(2) The deterioration coefficient is a constant; this assumption can be found in [40-42]. If the order quantity is $Q$, the products with a portion of $f$ will deteriorate, and the remainder of the products can be sold.

(3) The perceived quality of the product is $s_{q}$. When the food processor does not invest in additional processing efforts, $s_{q}=s+\varepsilon_{1}$; when the food processor invests in additional processing efforts, such as reopening or upgrading facilities for food processing or educating staff on how to ensure food safety practices, $s_{q}=q+\varepsilon_{2}$, where $\varepsilon_{1}$ and $\varepsilon_{1}$ are independent random variables, satisfying the distribution of mean value 0 and variance $\sigma_{i}^{2},(i=1$ or 2$)$.

(4) The utility of the customers when purchasing the products is the linear function of the retail price $p$ and the perceived quality $s_{q}$, and it is assumed to be downward sloping in retail price and upward sloping in perceived quality. Thus, the utility function can be denoted by $\mu=v+\beta s_{q}-p$.

(5) Since the customers' perceived quality of products is uncertain, it is assumed that the food processor is risk-averse, and the risk aversion indicator is $k$.

3.3. Model Construction and Analysis. According to Wen and Siqin [36], we assume that the customers' product valuations $(v)$ are uniformly distributed in $[0,1]$, namely, $v \sim U(0,1)$. The utility of the customer when buying the product with the selling price $p$ can be expressed as $\mu=v+\beta s_{q}-p$. When $\mu \geq 0$, the customer will buy the product. The market size is normalized to 1 , and the demand can be expressed as $D=1+\beta s_{q}-p$. Since the customer's perceived quality remains uncertain to the food processor, now we explore the impact of the food processor's risk attitudes on the equilibrium solutions. The valuation measure used herein is known in preference theory as the mean-variance approach (e.g., [43, 44]), whose form is expressed by the following equation: $U(\pi)=E(\pi)-(k \operatorname{Var}(\pi) / 2)$. We compare the optimal decisions of members based on different modes of payments and subsidies, trying to examine the combined effects of the payment mode and the subsidy on increasing customer demands. Mode 1 represents the order quantity-based payment, and mode 2 represents the demand-based payment.

3.3.1. The Optimal Solutions without Subsidy. When the food processor does not incur safety investment to improve the customers' belief towards the products' quality, it is supposed that the government does not intervene in the supply chain. Thus, the supply chain consists of a supplier and a leading food processor, and the decision sequence is shown in Figure 1.

The customer's perceived quality of the product satisfies $s_{q}=s+\varepsilon_{1}$, where $\varepsilon_{1}$ is a normally distributed random factor, with mean zero and variance $\sigma_{1}^{2}$. The order quantity in this paper includes customer demands and product deterioration. Two methods based on different payments are analyzed. One method is the order quantity-based payment, where the food processor pays the supplier based on the order quantity. The other method is the demandbased payment, where the deterioration cost $c(Q-D)$ is undertaken by the processor and the supplier together. Particularly, when $r=0$, the food processor will take on all deterioration costs, and when $r=1$, the supplier will take on all deterioration costs. The event sequence is defined as follows: (i) the food processor determines the marginal profit $m$ and orders products from the supplier at the beginning of sales cycle by taking the potential product decay into account; (ii) the supplier determines wholesale price $w$ (and a fixed deterioration cost-sharing proportion $r$ under the mode of demand-based payment); then, he transports the products to the destination market of the food processor; (iii) the decay occurs and the food processor sells the remaining products to the customers.

Case 1. Order quantity-based payment.

The food processor's expected order quantity is $\left(1+\beta s-p_{11}\right) l$, and the actual customer demand is $\left(1+\beta s-p_{11}\right)$. The quantity of deterioration is $\left(1+\beta s-p_{11}\right)(l-1)$. Since the food processor pays the supplier based on the order quantity, the supplier's expected profit can be represented by

$$
\begin{gathered}
\max _{w_{11}} E\left(\pi_{s 11}\right)=\left(w_{11}-c\right)\left(1+\beta s-\left(w_{11}+m_{11}\right)\right) l . \\
\text { Letting }\left(\partial E\left(\pi_{s 11}\right) / \partial w_{11}\right)=0 \text {, we get } \\
\qquad w_{11}^{*}\left(m_{11}\right)=\frac{1+c-m_{11}+s \beta}{2} .
\end{gathered}
$$


TABLE 1: Notation and explanation.

\begin{tabular}{|c|c|}
\hline Parameters & Definition \\
\hline$v$ & The heterogeneous customer valuation, $v \sim U(0,1)$ \\
\hline$s_{q}$ & Customers' perceived quality about food \\
\hline$\mu$ & The customer utility \\
\hline$f$ & Deterioration coefficient, which is positively correlated with the deterioration rate, $(1 / 1-f)=l$ \\
\hline$\beta$ & Nonnegative coefficient representing demand sensitivity to the product's perceived quality \\
\hline$c$ & The constant production cost per unit \\
\hline$k$ & The risk aversion indicator of the processor \\
\hline$\lambda$ & Cost coefficient of the safety investment \\
\hline$r$ & Fixed proportion of deterioration cost-sharing \\
\hline \multicolumn{2}{|c|}{ Decision variables: } \\
\hline$m$ & The marginal profit per unit \\
\hline$w$ & The wholesale price per unit \\
\hline$p$ & The selling price per unit, $p=w+m$ \\
\hline$q$ & The optimal safety investment \\
\hline$S$ & The government subsidy per unit \\
\hline \multicolumn{2}{|l|}{ Functions: } \\
\hline$D$ & The total demand during the whole sales cycle \\
\hline Q & $\begin{array}{l}\text { The total order quantity during the whole sales cycle. Since the product may undergo deterioration during the process of } \\
\text { transportation and sales, to satisfy demands, the retailer will set } Q=(E(D) / 1-f) \text {. To simplify the model, we denote } \\
\qquad(1 / 1-f)=l\end{array}$ \\
\hline $\mathrm{CS}(S)$ & Customer's surplus, which is a function of government subsidies \\
\hline $\operatorname{SW}(S)$ & Social welfare, which is a function of government subsidies \\
\hline$E\left(\pi_{r}\right)$ & Expected profit of the food processor during the whole sales cycle \\
\hline$E\left(\pi_{s}\right)$ & Expected profit of the supplier during the whole sales cycle \\
\hline$U\left(\pi_{r}\right)$ & Expected utility of the risk-averse processor during the whole sales cycle \\
\hline
\end{tabular}

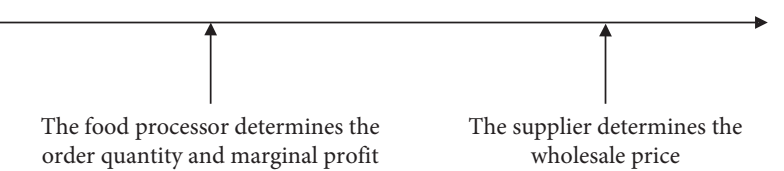

FIGURE 1: The decision sequence of supply chain members without safety investment.

As $\left(\partial^{2} E\left(\pi_{s 11}\right) / \partial w_{11}^{2}\right)=-2 l$, the expected profit function of the supplier is concave.

The food processor's expected profit is

$$
E\left(\pi_{r 11}\right)=\left(w_{11}+m_{11}-w_{11} l\right) D_{11} .
$$

The conditional variance of the profit is

$$
\operatorname{Var}\left(\pi_{r 11}\right)=\beta^{2}\left(w_{11}+m_{11}-w_{11} l\right)^{2} \sigma_{1}^{2},
$$

and the food processor's utility can be defined as

$$
\begin{aligned}
\max _{m_{11}} U\left(\pi_{r 11}\right)= & \left(w_{11}+m_{11}-w_{11} l\right) D_{11} \\
& -\frac{k}{2} \beta^{2}\left(w_{11}+m_{11}-w_{11} l\right)^{2} \sigma_{1}^{2} .
\end{aligned}
$$

Substituting $w_{11}^{*}\left(m_{11}\right)$ into (5), by letting $\left(\partial U\left(\pi_{r 11}\right) / \partial m_{11}\right)=0$, we can obtain

$$
m_{11}=\frac{2(-c+l(1+s \beta))+k\left(l^{2}-1\right) \beta^{2}(1+c+s \beta) \sigma_{1}^{2}}{(1+l)\left(2+k(1+l) \beta^{2} \sigma_{1}^{2}\right)} .
$$

As $\left(\partial^{2} U\left(\pi_{r 11}\right) / \partial m_{11}^{2}\right)=-(1 / 4)(1+l)\left(2+k(1+l) \beta^{2} \sigma_{1}^{2}\right)$ $<0$, the expected utility function of the food processor is concave.

Substituting (6) into (2), we can obtain

$$
w_{11}=\frac{(1+c(2+l)+s \beta)+k(1+l) \beta^{2}(1+c+s \beta) \sigma_{1}^{2}}{(1+l)\left(2+k(1+l) \beta^{2} \sigma_{1}^{2}\right)} \text {. }
$$

Combing (6) and (7), we can get the optimal decisions as shown in Table 2.

Case 2. Demand-based payment.

The deterioration cost $c\left(Q_{12}-D_{12}\right)$ is undertaken by the processor and the supplier together; particularly, when $r=0$, the food processor will take on all deterioration costs, and when $r=1$, the supplier will take on all deterioration costs. The supplier's expected profit can be represented by

$$
\max _{w_{12}} E\left(\pi_{s 12}\right)=\left(w_{12}-c\right) D_{12}-r c\left(Q_{12}-D_{12}\right) \text {. }
$$

As $\left(\partial^{2} E\left(\pi_{s 12}\right) / \partial w_{12}^{2}\right)=-2$, the expected profit function of the supplier is concave.

The food processor's utility can be defined as

$$
\begin{aligned}
\max _{m_{12}} U\left(\pi_{r 12}\right)= & m_{12} D_{12}-(1-r) c\left(Q_{12}-D_{12}\right) \\
& -\frac{k}{2} \beta^{2}\left(m_{12}-c(l-1)(1-r)\right)^{2} \sigma_{1}^{2} .
\end{aligned}
$$




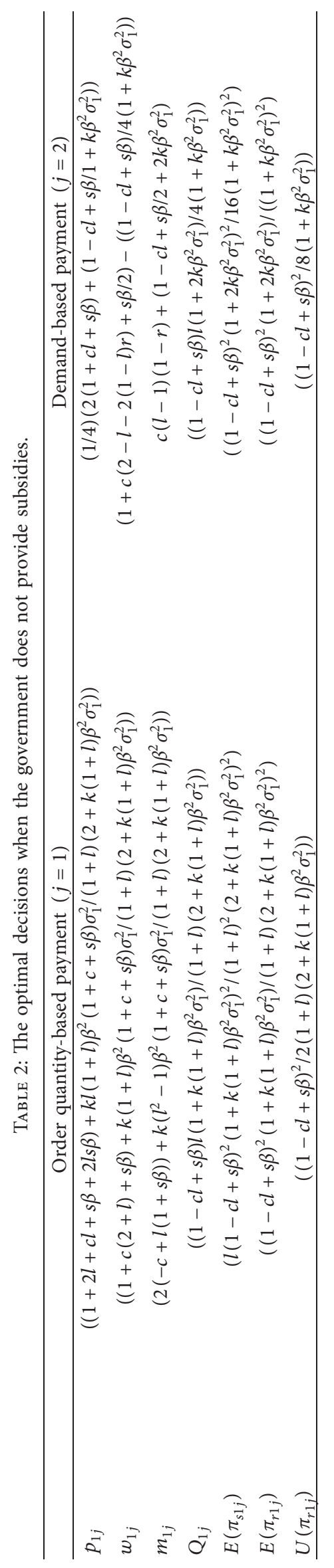


As $\left(\partial^{2} U\left(\pi_{r 12}\right) / \partial m_{12}^{2}\right)=-1-k \beta^{2} \sigma_{1}^{2}<0$, the expected utility function of the food processor is concave.

Similarly, we can get the optimal decisions as shown in Table 2.

Proposition 1. When the risk-averse food processor does not adopt safety investment,

(i) The selling price and the expected utility of the food processor decrease with $k$.

(ii) The wholesale price and the expected utility of the supplier increase with $k$.

All proofs are given in the Appendix.

Proposition 1 shows that the risk-averse food processor is inclined to lower the selling price, leading to a lower utility. Meanwhile, the food processor's expected utility will be weakened. We find that the suppliers can benefit from the risk aversion of the food processor. This can be explained by the fact that a lower selling price leads to more demands, and thus the food processor tends to order more products from the supplier. The supplier will increase the wholesale price with the increase of customer demands. Therefore, the supplier will obtain more profits due to a higher wholesale price and more customer demands.

Proposition 2. When the risk-averse food processor does not adopt safety investment, the food processor can obtain more demands and higher utility under the mode of demand-based payment.

Proposition 2 shows that when the risk-averse food processor does not adopt safety investment, the customer demand is higher under the mode of demand-based payment. However, the supplier will benefit from the demandbased payment only when $(1+l)\left(1+2 k \sigma_{1}^{2} \beta^{2}\right)(2+k$ $\left.\sigma_{1}^{2} \beta^{2}(1+l)\right)>4 \sqrt{l}\left(1+k \sigma_{1}^{2} \beta^{2}\right)\left(1+k \sigma_{1}^{2} \beta^{2}(1+l)\right)$. Particularly, the food processor will be risk-neutral when $k=0$, and the supplier here will always benefit from the demand-based payment.

3.3.2. The Optimal Solutions with Subsidy. When the food processor adopts additional safety investment, the average perceived quality of the product changes from $s$ to $q$, and the cost is $(\lambda / 2)(q-s)^{2}$. The actual perceived quality of the product satisfies $s_{q}=q+\varepsilon_{2}$, and the government here subsidizes the food processor $S q$ in total. The decision here follows a three-stage process, in which the government acts as the leader and decides the subsidy $S$, the food processor then determines the marginal profit $m$ and the safety investment $q$, and the supplier finally decides the wholesale price $w$. The decision sequence is shown in Figure 2. Using the backwards induction, we first assume that the subsidy, the marginal profit, and safety investment are known, and the supplier determines the optimal wholesale price by profit maximization. Then, the food processor determines the optimal marginal profit and safety investment by utility maximization. Finally, the government determines the optimal subsidy based on social welfare maximization.

Case 3. Order quantity-based payment.

The food processor's expected order quantity is $\left(1+\beta q_{21}-p_{21}\right) l$, and the actual customer demand is $\left(1+\beta q_{21}-p_{21}\right)$. The quantity of deteriorating products is $\left(1+\beta q_{21}-p_{21}\right)(l-1)$. Since the food processor pays the supplier based on the order quantity, the supplier's expected profit can be represented by

$$
\max _{w_{21}} E\left(\pi_{s 21}\right)=\left(w_{21}-c\right)\left(1+\beta q_{21}-p_{21}\right) l .
$$

Letting $\left(\partial E\left(\pi_{s 21}\right) / \partial w_{21}\right)=0$, we get

$$
w_{21}^{*}\left(m_{21}\right)=\frac{1+c-m_{21}+q_{21} \beta}{2} .
$$

As $\left(\partial^{2} E\left(\pi_{s 21}\right) / \partial w_{21}^{2}\right)=-2 l$, the expected profit function of the supplier is concave. by

The food processor's expected profit can be represented

$$
E\left(\pi_{r 21}\right)=\left(w_{21}+m_{21}-w_{21} l\right) D_{21}+S_{21} q_{21}-\frac{\lambda}{2}\left(q_{21}-s\right)^{2} .
$$

The conditional variance of the profit is

$$
\operatorname{Var}\left(\pi_{r 21}\right)=\beta^{2}\left(w_{21}+m_{21}-w_{21} l\right)^{2} \sigma_{2}^{2},
$$

and the food processor's utility can be defined as

$$
\begin{aligned}
U\left(\pi_{r 21}\right)= & \left(w_{21}+m_{21}-w_{21} l\right) D_{21}+S_{21} q_{21}-\frac{\lambda}{2}\left(q_{21}-s\right)^{2} \\
& -\frac{k}{2} \beta^{2}\left(w_{21}+m_{21}-w_{21} l\right)^{2} \sigma_{2}^{2} .
\end{aligned}
$$

As $\quad\left(\partial^{2} U\left(\pi_{r 21}\right)\right) /\left(\partial m_{21}^{2}\right)=-(1 / 4)(1+l)(2+k(1+l)$ $\left.\beta^{2} \sigma_{2}^{2}\right)<0, \quad\left(\partial^{2} U\left(\pi_{r 21}\right)\right) /\left(\partial q_{21}^{2}\right)=(1 / 4)\left(2(1-l) \beta^{2}-4 \lambda-\right.$ $\left.k(-1+l)^{2} \beta^{4} \sigma_{2}^{2}\right)<0,\left(\partial^{2} U\left(\pi_{r 21}\right)\right) /\left(\partial m_{21} \partial q_{21}\right)=(1 / 4)(2 l \beta+$ $\left.k\left(-1+l^{2}\right) \beta^{3} \sigma_{2}^{2}\right)$, we get $\left(\partial^{2} U\left(\pi_{r 21}\right)\right) /\left(\partial m_{21}^{2}\right)\left(\partial^{2} U\left(\pi_{r 21}\right)\right) /$ $\left(\partial q_{21}^{2}\right)-\left(\partial^{2} U\left(\pi_{r 21}\right)\right) /\left(\partial m_{21} \partial q_{21}\right)^{2}=(1 / 4)\left(-\beta^{2}+2(1+l) \lambda\right.$ $\left.+k(1+l)^{2} \beta^{2} \lambda \sigma_{2}^{2}\right)>0$. Therefore, when $1 / 4\left(-\beta^{2}+2(1+l) \lambda+\right.$ $\left.k(1+l)^{2} \beta^{2} \lambda \sigma_{2}^{2}\right)>0$, the expected utility function of the food processor is concave. 

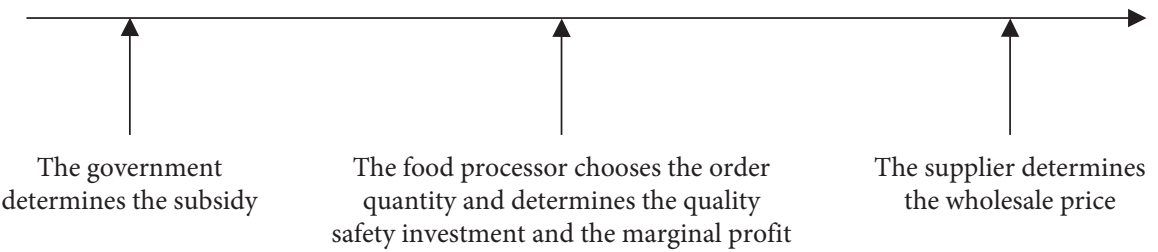

The supplier determines

the wholesale price

FIgURE 2: The decision sequence of supply chain members with safety investment.

Substituting $w_{21}^{*}\left(m_{21}\right)$ into (14), by letting $\left(\partial U\left(\pi_{r 21}\right) / \partial m_{21}\right)=\left(\partial U\left(\pi_{r 21}\right) / \partial q_{21}\right)=0$, we can obtain

$$
\begin{aligned}
& m_{21}=\frac{\left(\left(l \beta\left(2 S_{21}-c \beta\right)+2 l(1+s \beta) \lambda+c\left(\beta^{2}-2 \lambda\right)\right)+k\left(l^{2}-1\right) \beta^{2}\left(S_{21} \beta+(1+c+s \beta) \lambda\right) \sigma_{2}^{2}\right)}{\left(2(1+l) \lambda+\beta^{2}\left(k(1+l)^{2} \lambda \sigma_{2}^{2}-1\right)\right)}, \\
& q_{21}=\frac{\left(2(1+l) S_{21}-c l \beta+2(1+l) s \lambda\right)+\beta\left(1+k(1+l)^{2} \beta\left(S_{21}+s \lambda\right) \sigma_{2}^{2}\right)}{2(1+l) \lambda+\beta^{2}\left(k(1+l)^{2} \lambda \sigma_{2}^{2}-1\right)} .
\end{aligned}
$$

Substituting (15) and (16) into (11), we can obtain

$$
w_{21}=\frac{(1+c(2+l)+s \beta)+k(1+l) \beta^{2}(1+c+s \beta) \sigma_{2}^{2}}{(1+l)\left(2+k(1+l) \beta^{2} \sigma_{2}^{2}\right)} .
$$

Combing (15), (16), and (17), we can get the optimal decisions as shown in Table 3.

Case 4. Demand-based payment.

The quantity of deteriorating products is $\left(1+\beta q_{22}-p_{22}\right)(l-1)$. The deterioration cost $c\left(Q_{22}-D_{22}\right)$ is undertaken by the processor and the supplier together; particularly, when $r=0$, the food processor will take on all deterioration costs, and when $r=1$, the supplier will take on all deterioration costs. The supplier's expected profit can be represented by

$$
\begin{aligned}
\max _{w_{22}} E\left(\pi_{s 22}\right)= & \left(w_{22}-c\right) D_{22}-r c\left(Q_{22}-D_{22}\right) \\
= & \left(w_{22}-c-r c(l-1)\right) \\
& \cdot\left(1+\beta q_{22}-\left(w_{22}+m_{22}\right)\right) .
\end{aligned}
$$

As $\left(\partial^{2} E\left(\pi_{s 22}\right) / \partial w_{22}^{2}\right)=-2 l$, the expected profit function of the supplier is concave.

The food processor's utility can be defined as

$$
\begin{aligned}
\max _{q_{22}, m_{22}} U\left(\pi_{r 22}\right)= & m_{22} D_{22}-(1-r) c\left(Q_{22}-D_{22}\right)+S_{22} q_{22} \\
& -\frac{\lambda}{2}\left(q_{22}-s\right)^{2}-\frac{k}{2} \beta^{2} \\
& \cdot\left(m_{22}-c(l-1)(1-r)\right)^{2} \sigma_{2}^{2} .
\end{aligned}
$$

As $\left(\partial^{2} U\left(\pi_{r 22}\right)\right) /\left(\partial m_{22}^{2}\right)=-1-k \beta^{2} \sigma_{2}^{2}<0, \quad\left(\partial^{2} U\left(\pi_{r 22}\right) /\right.$ $\left.\partial q_{22}^{2}\right)=-\lambda<0, \quad\left(\partial^{2} U\left(\pi_{r 22}\right)\right) /\left(\partial m_{22} \partial q_{22}\right)=\beta / 2$, we get $\left(\partial^{2} U\left(\pi_{r 22}\right)\right) /\left(\partial m_{22}^{2}\right)\left(\partial^{2} U\left(\pi_{r 22}\right) / \partial q_{22}^{2}\right)-\left(\partial^{2} U\left(\pi_{r 22}\right)\right)$ / $\left(\partial m_{22} \partial q_{22}\right)^{2}=-\left(\beta^{2} / 4\right)+\lambda+k \beta^{2} \lambda \sigma_{2}^{2}>0$, the expected utility function of the food processor is concave. Therefore, to ensure the joint concavity of expected utility function of the food processor on $\left(m_{21}, q_{21}\right)$, $\left(m_{22}, q_{22}\right)$, $\lambda>\left(\beta^{2} / 4\left(1+k \beta^{2} \sigma_{2}^{2}\right)\right)$ is needed.

Proposition 3. When the risk-averse food processor adopts safety investment strategy, if the subsidy is fixed $\left(S_{21}=S_{22}\right)$,

(i) The safety investment, the selling price, and the utility of the food processor decrease with $k$.

(ii) If the food processor pays the supplier based on the order quantity, and if the customer's quality sensitivity $\beta<(>) \sqrt{(1+l) \lambda}$, the wholesale price and the expected profit of the supplier increase (decrease) with $k$.

(iii) If the food processor pays the supplier based on the customer demand, and if the customer's quality sensitivity $\beta<(>) \sqrt{2 \lambda}$, the wholesale price and the expected profit of the supplier increase (decrease) with $k$.

Proposition 3 shows that risk aversion discourages retailers from adopting safety investment strategy. Meanwhile, the food processor will reduce the selling price, resulting in a lower expected utility. When the customers are less sensitive to the perceived quality, e.g., $\beta<\sqrt{(1+l) \lambda}$ under the method of order quantity-based payment or $\beta<\sqrt{2 \lambda}$ under the method of demand-based payment, the suppliers still benefits from the food processor's risk aversion behavior. When the customers are more sensitive to the perceived quality, the safety investment will decrease with the risk aversion indicator, weakening customer demands seriously. The supplier tends to reduce the wholesale price to mitigate the decrease of customer demands, but it still leads to profit loss. 


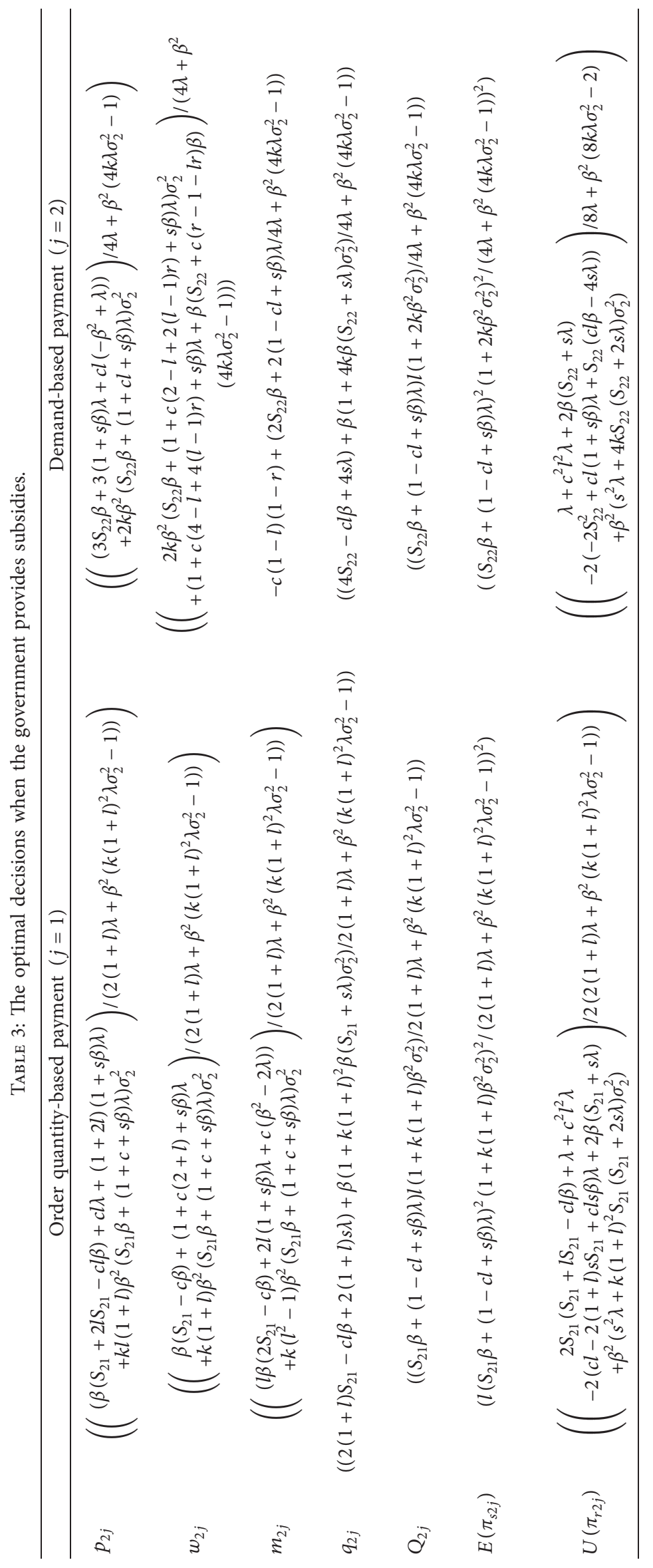


Proposition 4. When the government subsidy is fixed $\left(S_{21}=S_{22}=S\right)$, if the food processor pays the supplier based on the customer demand, the food processor will invest in more safety efforts and obtain more demands and higher utility.

Proposition 4 shows that when the subsidy is fixed, if the food processor pays the supplier based on the demand and the supplier shares a portion of the deterioration costs, the food processor will benefit from investing in more safety efforts. However, the supplier will benefit from the demandbased payment only when $(1+l)\left(1+2 k \sigma_{2}^{2} \beta^{2}\right)(2+(1+$ l) $\left.k \sigma_{2}^{2} \beta^{2}\right)>4 \sqrt{l}\left(1+k \sigma_{2}^{2} \beta^{2}\right)\left(1+(1+l) k \quad \sigma_{2}^{2} \beta^{2}\right)$. Particularly, the food processor will be risk-neutral when $k=0$, and the supplier will always benefit from the demand-based payment.

The above analysis is based on the fixed government subsidy. Using the backwards induction, the government finally decides the optimal subsidy by maximizing social welfare. The social welfare function CS $(S)$ constructed in this paper consists of the following parts:

(1) Customer surplus, CS $(S)$ : as commonly defined in the literature (e.g., $[45,46])$, we obtain the function of customer surplus as follows:

$$
E(\mathrm{CS})=E\left(\int_{p-\beta s_{q}}^{1}\left(v+\beta s_{q}-p\right) f(v) \mathrm{d} v\right)=\frac{\left(1-p+\beta s_{q}\right)^{2}}{2} .
$$

(2) Supplier chain's profit: it is calculated as follows:

$$
E\left(\pi_{s c 2 i}\right)=\left(p_{2 i}-c l\right) D_{2 i}+S_{2 i} q_{2 i}-\frac{\lambda}{2}\left(q_{2 i}-s\right)^{2}
$$

(3) Subsidy expense.

Combining components (1), (2), and (3), the total social welfare in case 3 and case 4 for a given $S_{2 j}$ is

$$
\begin{aligned}
\max _{S_{2 j}} S W_{2 j}= & \left(p_{2 j}-c l\right)\left(1-p_{2 j}+\beta q_{2 j}\right)+\frac{\left(1-p_{2 j}+\beta q_{2 j}\right)^{2}}{2} \\
& -\frac{\lambda}{2}\left(q_{2 j}-s\right)^{2} .
\end{aligned}
$$

The problem to be solved by the government (Stackelberg leader) is to determine the subsidy $S_{2 j}$ that would maximize the total social welfare; finally, we can obtain the optimal subsidy as shown in Proposition 5.

Proposition 5. When the food processor is risk-averse, the government's optimal subsidy under different payment modes can be expressed as

(i) If the food processor pays the food supplier based on the order quantity and if $\lambda>\max \left\{\left(\beta^{2}(3+4 l+k(1+\right.\right.$ l) $\left.\beta^{2} \sigma_{2}^{2}\left(4+6 l+k(1+l)(1+2 l) \beta^{2} \sigma_{2}^{2}\right)\right) /(1+l)^{2}(2+k$ $\left.\left.\left.(1+l) \beta^{2} \sigma_{2}^{2}\right)^{2}\right), \lambda>\left(\beta^{2} / 4\left(1+k \beta^{2} \sigma_{2}^{2}\right)\right)\right\}, S_{21}=(\beta(1-$ $c l+s \beta) \lambda\left(-(1+2 l)-k(1+l)(3+5 l) \quad \beta^{2} \sigma_{2}^{2}-k^{2}(1+\right.$ $\left.l)^{2}(1+2 l) \beta^{4} \sigma_{2}^{4}\right) /\left(k^{2}(1+l)^{2}(1+2 l) \beta^{6} \sigma_{2}^{4}-4(1+l)^{2}\right.$ $\lambda+\beta^{2}\left(3+4 l-4 k(1+l)^{3} \lambda \sigma_{2}^{2}\right)+k \beta^{4} \sigma_{2}^{2}(2(1+l)(2+$ $\left.\left.\left.3 l)-k(1+l)^{4} \lambda \sigma_{2}^{2}\right)\right)\right)$.

(ii) If the food processor pays the food supplier based on the demand and if $\lambda>\max \left\{\left(\beta^{2}(1+2 k\right.\right.$ $\left.\left.\beta^{2} \sigma_{2}^{2}\right)\left(7+6 k \beta^{2} \sigma_{2}^{2}\right) / 16\left(1+k \beta^{2} \sigma_{2}^{2}\right)^{2}\right), \lambda>\quad\left(\beta^{2} / 4(1+\right.$ $\left.\left.\left.k \beta^{2} \sigma_{2}^{2}\right)\right)\right\}, S_{22}=\left(\beta(1-c l+s \beta) \lambda\left(3+16 k \beta^{2} \sigma_{2}^{2}+12 k^{2}\right.\right.$ $\left.\beta^{4} \sigma_{2}^{4}\right) /\left(16 \lambda-12 k^{2} \beta^{6} \sigma_{2}^{4}+4 k \beta^{4} \sigma_{2}^{2} \quad\left(4 k \lambda \sigma_{2}^{2}-5\right)+\beta^{2}\right.$ $\left.\left.\left(32 k \lambda \sigma_{2}^{2}-7\right)\right)\right)$.

Proposition 5 shows that only when the safety investment cost is large, the government will provide subsidies. In order to further analyze the influence of other parameters on the decision of government subsidy, this paper further assumes $k=0.3, \beta=0.6, \sigma_{2}^{2}=1, \lambda=0.5, s=0.5$, and $c=0.1$ in Figure $3(\mathrm{a})$ to study the effect of deterioration coefficient on the decision of government subsidy. It assumes $l=1.1$, $\beta=0.6, \sigma_{2}^{2}=1, \lambda=0.5, s=0.5$, and $c=0.1$ in Figure $3(\mathrm{~b})$ to study the effect of the risk aversion indicator on the decision of government subsidy.

To ensure $\lambda>\left(\beta^{2} / 4\left(1+k \beta^{2} \sigma_{2}^{2}\right)\right), \quad \lambda>0.0812 \quad$ and $\lambda>(0.09 / 1+0.36 k)$ are needed in Figures $3(\mathrm{a})$ and $3(\mathrm{~b})$, respectively. Figure $3(\mathrm{a})$ is divided into regions (A), (B), and (C), and Figure 3(b) is divided into regions (A), (B), (C), and (D). The regions where the government can maximize social welfare by providing subsidies under order quantitybased payment are (B) and (C), and that under demandbased payment is (C). Figures $3(\mathrm{a})$ and $3(\mathrm{~b})$ show that the government is more inclined to provide subsidies under order quantity-based payment. The government does not provide subsidies in regions (A) and (D). Figure 3(a) shows that when $\lambda$ is very small, the government does not provide subsidies under two methods; when $l$ and $\lambda$ are both relatively small, the government does not provide subsidies under the mode of order quantity-based payment; the decision of subsidies is not affected by $l$ under the method of demand-based payment. Figure 3(b) shows that when $\lambda$ is very small or when $k$ is greater than a threshold and $\lambda$ is relatively small, the government does not provide subsidies. This implies that although the subsidy increases with $k$ (see Proposition 6 (i)), a too high-risk aversion indicator will discourage the government from providing subsidies.

Proposition 6. When the government decides the subsidy,

(i) The subsidy increases with $k$.

(ii) The safety investment increases with $k$.

(iii) The supplier's profit increases with $k$.

(iv) The customer demand will be higher if the food processor pays the supplier based on the demand.

Proposition 6 shows that when the government decides the subsidy, in order to encourage the risk-averse food processors to invest in more efforts, the optimal subsidy 


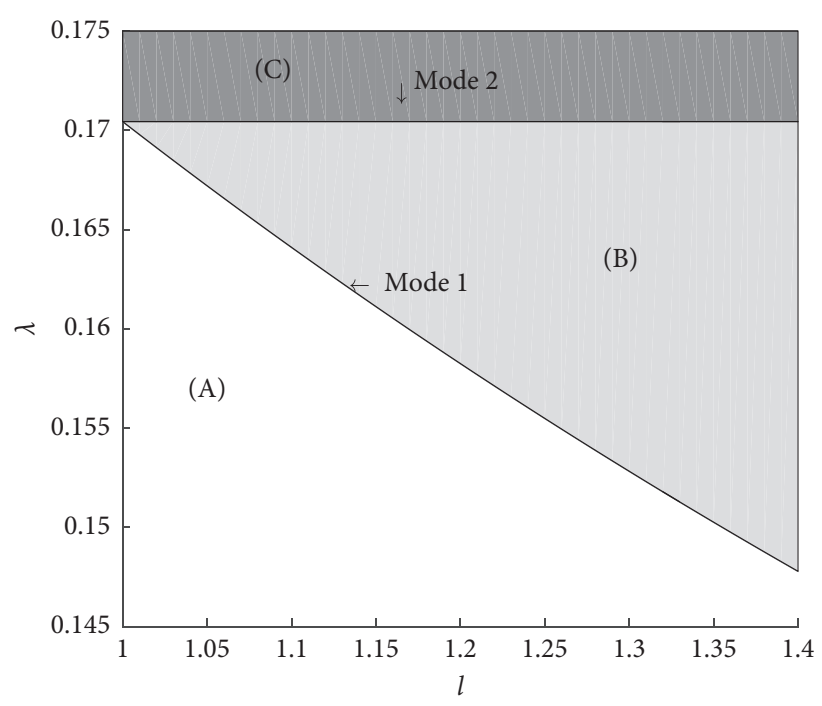

(a)

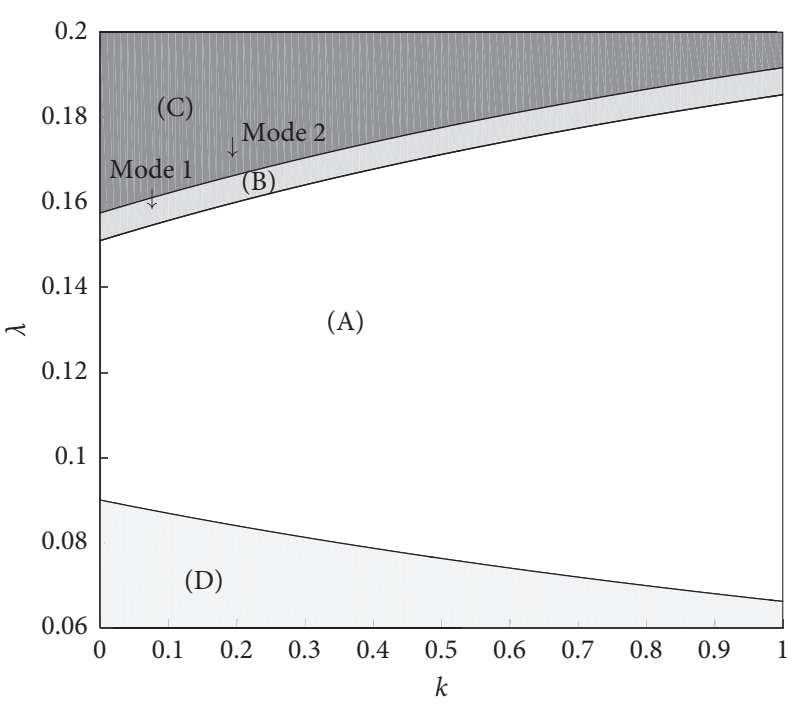

(b)

Figure 3: (a) The government decision on the subsidy as $l$ changes. (b) The government decision on the subsidy as $k$ changes.

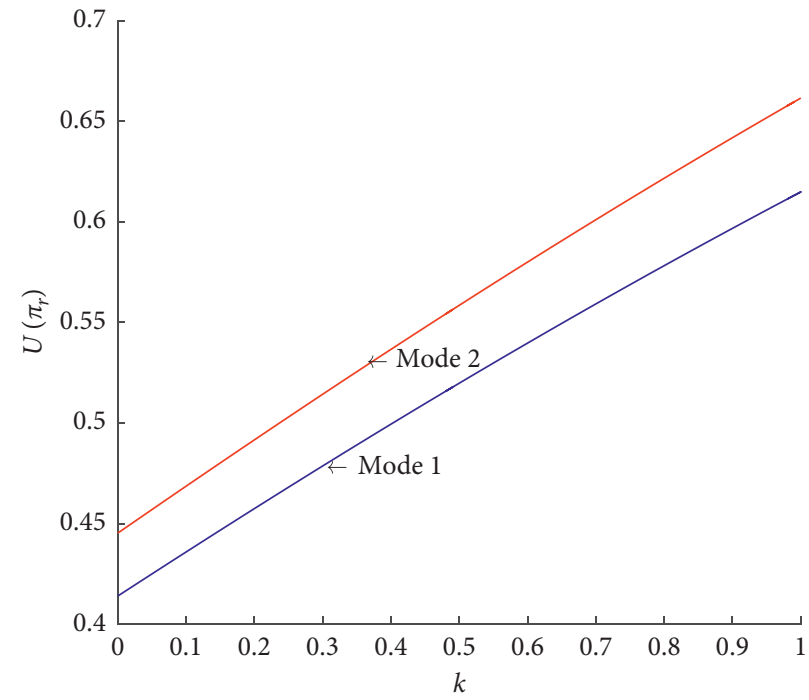

(a)

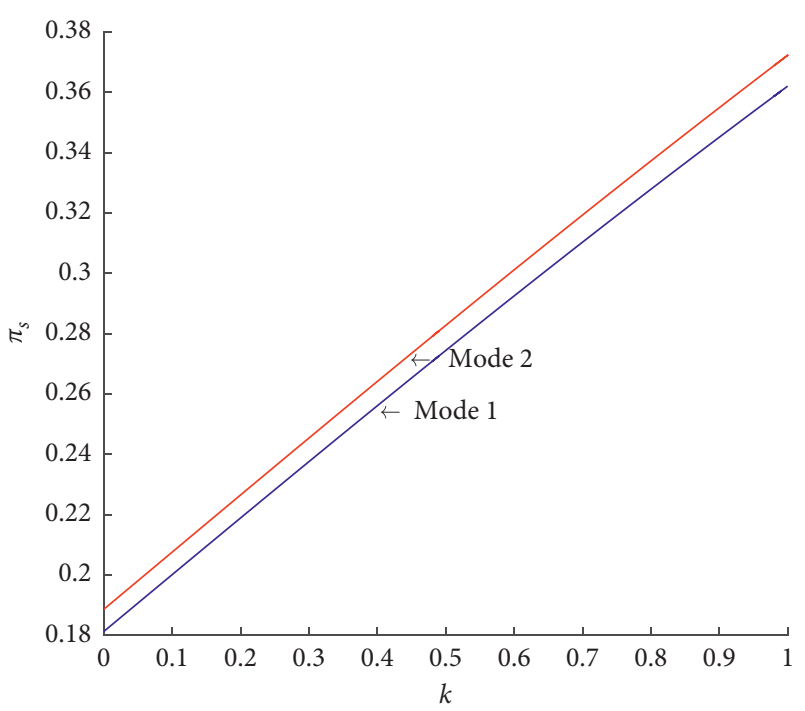

(b)

FIgURE 4: (a) The food processor's utility as $k$ changes. (b) The supplier's profit as $k$ changes.

increases with the food processor's risk aversion indicator. Different from Proposition 3, the supplier here always benefits from the food processor's risk-averse behavior. This can be explained by the fact that the subsidy here can increase the wholesale price and the demand; therefore, Proposition 6 shows that the supplier's profit always increases with $k$. Combining Proposition 2, Proposition 4, and Proposition 6 (iv), it can be concluded that the customer demand will increase under the method of demand-based payment. Therefore, from the perspective of increasing market share, it is necessary for suppliers to share a part of the food processor's deterioration costs.

\section{Numerical Simulation}

This part makes numerical experiments to analyze the effects of the food processor's risk aversion coefficient, deterioration coefficient on the food processor's expected utility, the supplier's profit, and the social welfare.

4.1. The Effects of Risk Aversion Coefficient on the Food Processor's Expected Utility and the Supplier's Profit When the Government Provides Subsidies. When we study the impact of the food processor's risk aversion coefficient on the 


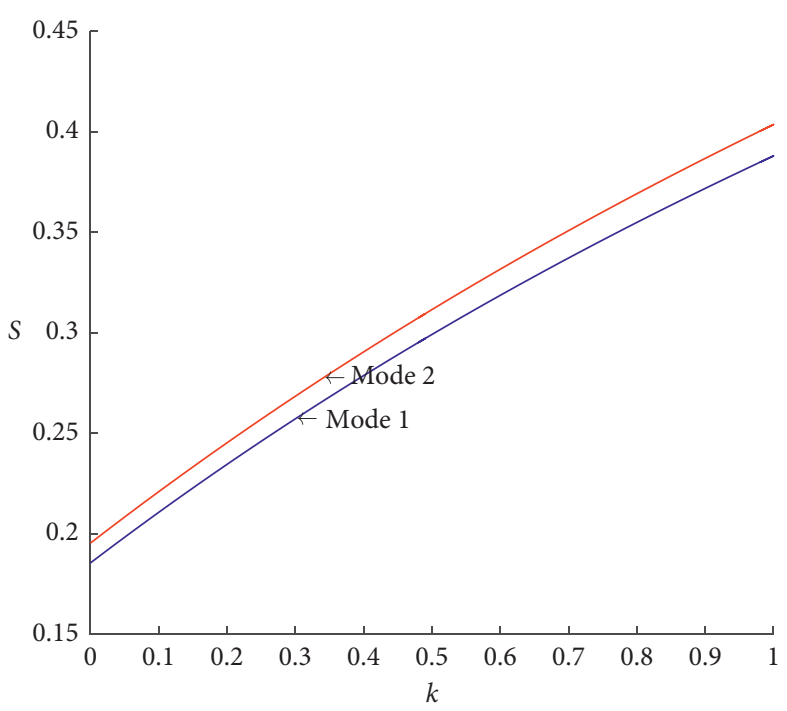

(a)

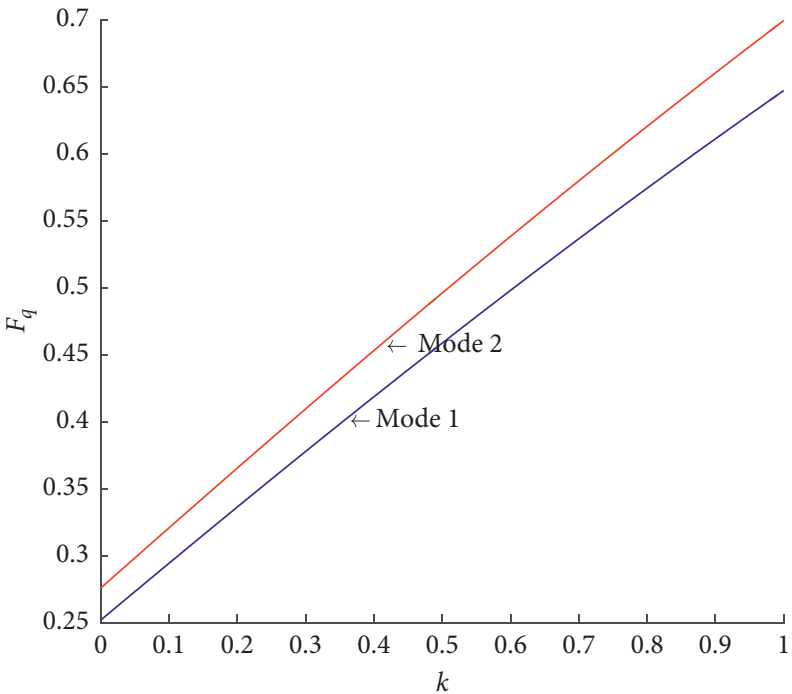

(c)

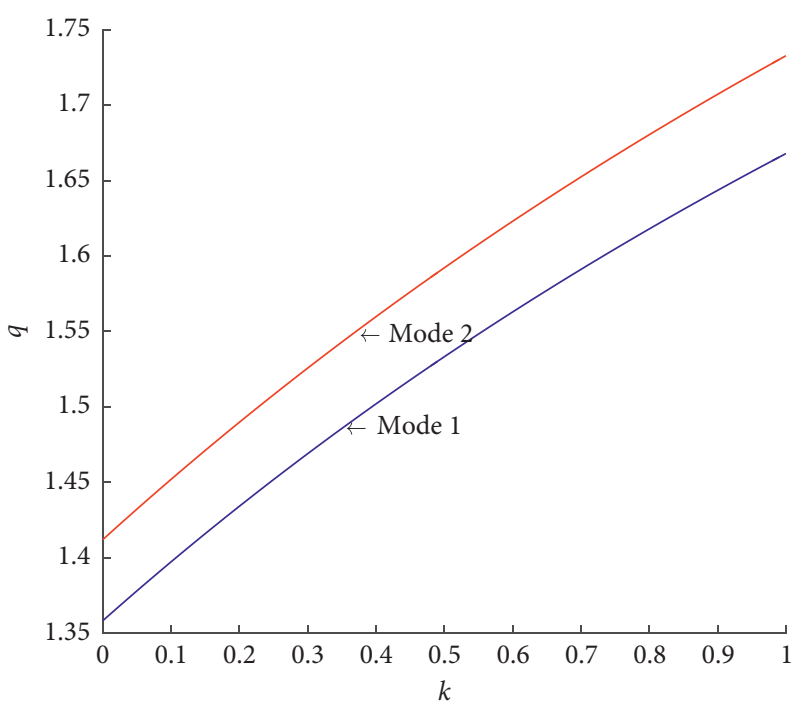

(b)

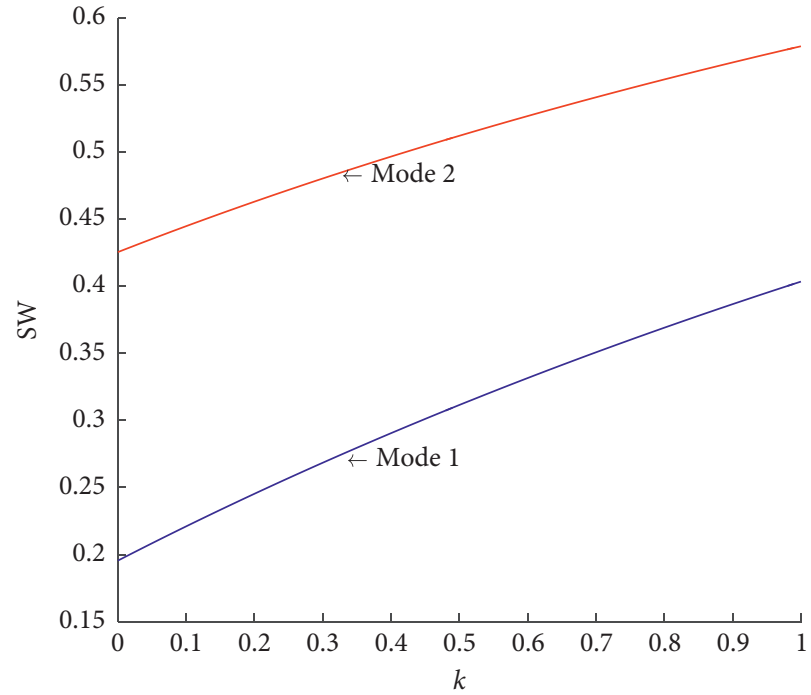

(d)

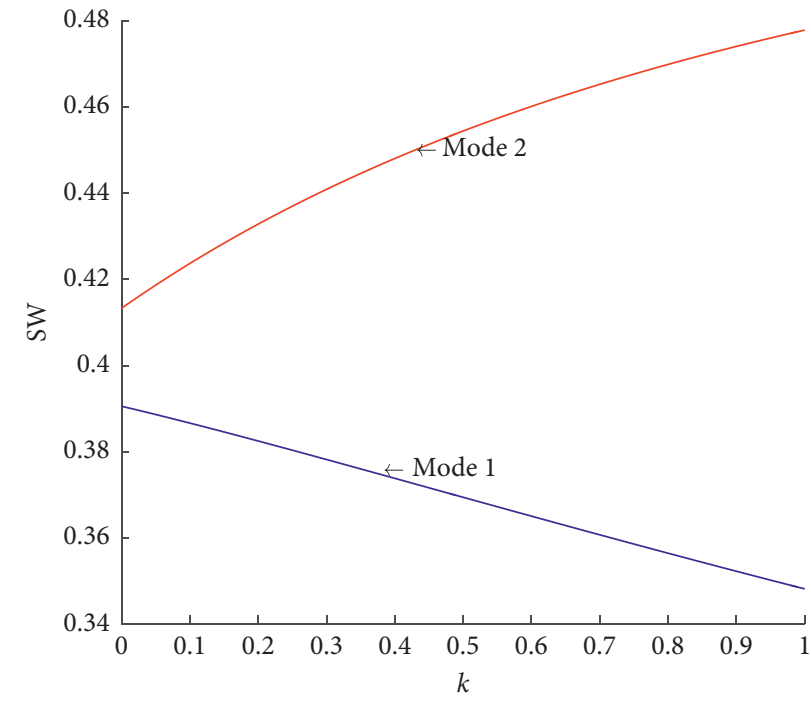

(e)

FIgURE 5: (a) The government subsidy as $k$ changes. (b) The safety investment as $k$ changes. (c) The government expenditure as $k$ changes. (d) The social welfare as $k$ changes when the government decides the subsidy. (e) The social welfare as $k$ changes when $S=0$. 


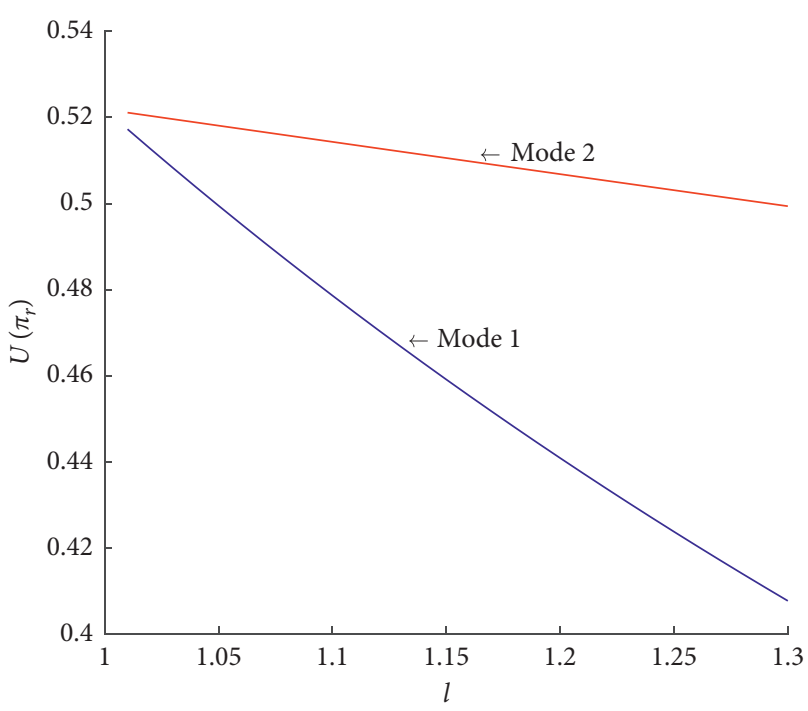

(a)

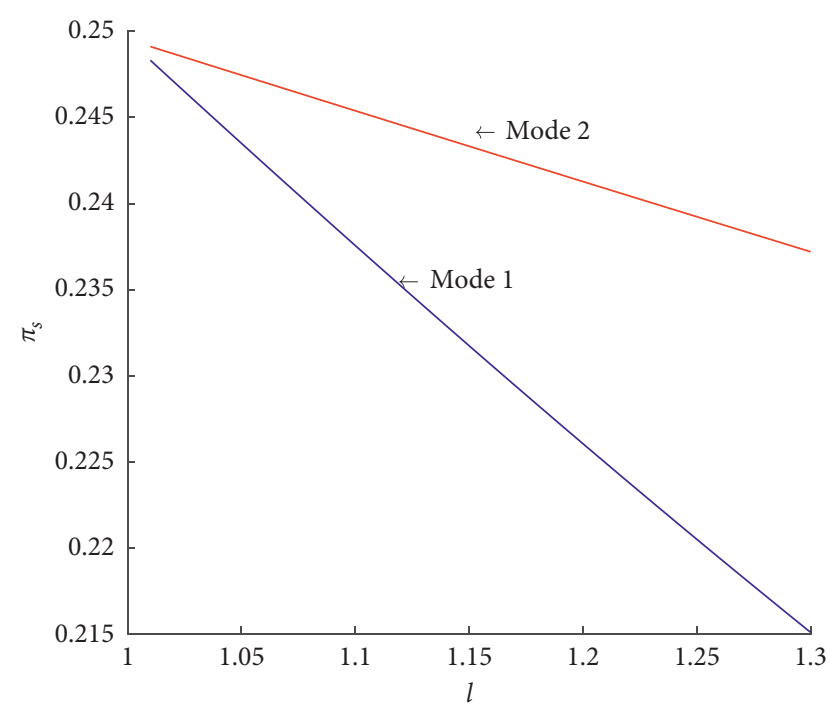

(b)

FIgURE 6: (a) The food processor's utility as $l$ changes. (b) The supplier's profit as $l$ changes.

decisions, we assume that $l=1.1, \beta=0.6, \sigma_{2}^{2}=1, \lambda=0.5$, $s=0.5$, and $c=0.1$.

As can be seen from Figure 4(a), the food processor's utility increases with the risk-averse indicator. This is because the government tends to subsidize the food processor more to encourage the risk-averse food processor to carry out safety investment. Figure 4(a) also shows that the food processor's expected utility under the method of demandbased payment is greater than that under the method of order quantity-based payment. Figure 4(b) shows that the supplier's profit increases with the food processor's risk aversion indicator, which verifies Proposition 6 (iii). Figure 4(b) shows that suppliers can obtain more profits under the method of demand-based payment. Combining Figures 4(a) and 4(b), we find when the government endogenously decides the subsidy, the demand-based payment can improve the supplier's profit and the food processor's utility. When the government provides endogenous subsidy, it is necessary for the food supplier to share a portion of deterioration costs. As the government provides higher subsidy facing a more risk-averse food processor, risk aversion will benefit supply chain members.

\subsection{The Effects of Risk Aversion Coefficient on Government} Subsidies, Safety Investment, and Social Welfare. Figures 5(a) and 5(b) show that when the government decides the subsidy, as the food processor is more riskaverse, the government will provide higher subsidies. This also encourages food processors to invest in more efforts and obtain more subsidies. As the per-unit subsidy and subsidy quantity (the amount of safety investment) under the method of demand-based payment are higher than those under the method of order quantity-based payment, the total government expenditure under the method of demand-based payment is larger, and Figure 5(c) validates it. Figure 5(d) shows that the demand-based payment can lead to a higher social welfare, and the social welfare increases with $k$ when the government decides the subsidy. When the government does not provide the subsidy, Figure 5(e) shows that the social welfare decreases with $k$ under the method of order quantity-based payment, whereas the social welfare increases with $k$ under the method of demand-based payment. Comparing Figures 5(d) and 5(e), we find the demand-based payment is beneficial to the social welfare no matter whether the government provides subsidies or not. When the government does not provide subsidies, it is necessary for the food processor to reduce risk aversion under the mode of order quantity-based payment from the perspective of social welfare. However, if two members adopt demand-based payment, risk aversion will benefit social welfare.

4.3. The Effects of Deterioration Coefficient on the Food Processor's Expected Utility and the Supplier's Profit When the Government Provides Subsidies. When we study the effects of deterioration coefficient on the decisions, we assume that $k=0.3, \beta=0.6, \sigma_{2}^{2}=1, \lambda=0.5, s=0.5$, and $c=0.1$.

Figures 6(a) and 6(b) show that the demand-based payment is a better method for supply chain members, and the gap between the demand-based payment and the order quantity-based payment increases with $l$. However, the supplier's profit and the food processor's utility will decrease with $l$.

4.4. The Effects of Deterioration Coefficient on Government Subsidies, Safety Investment, and Social Welfare When the Government Provides Subsidies. As shown in Figure 7(a), the unit government subsidy decreases as $l$ increases, discouraging food processors from investing in safety investment 


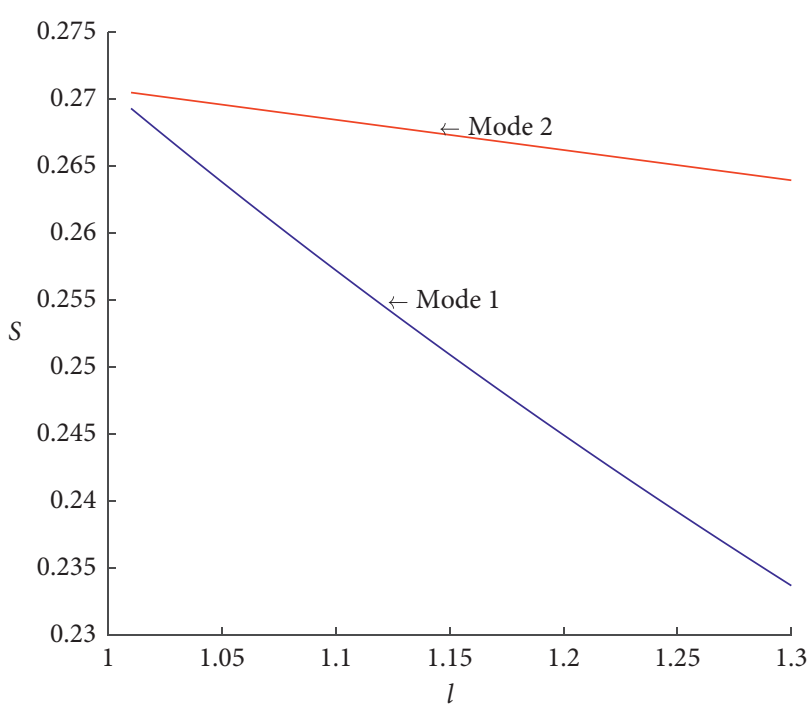

(a)

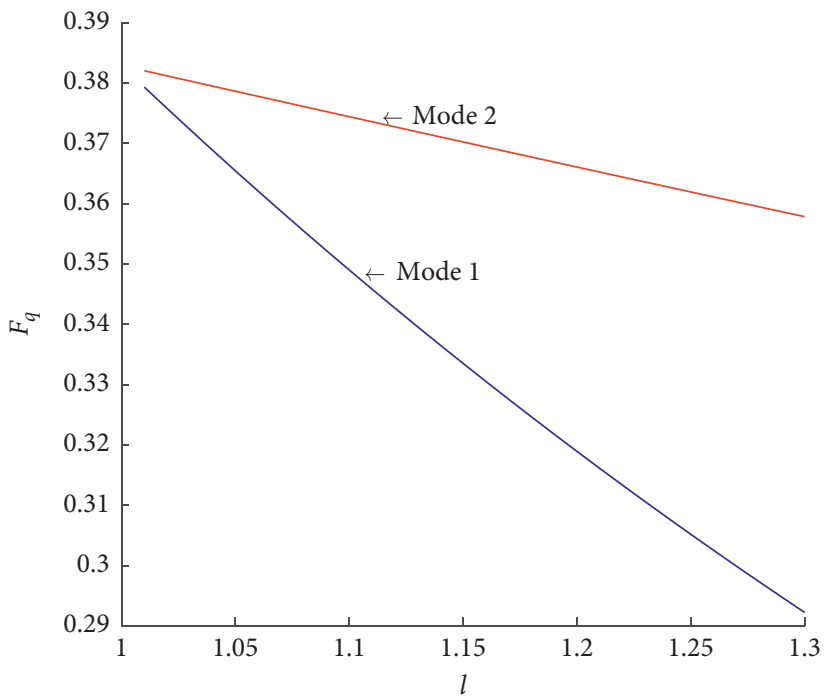

(c)

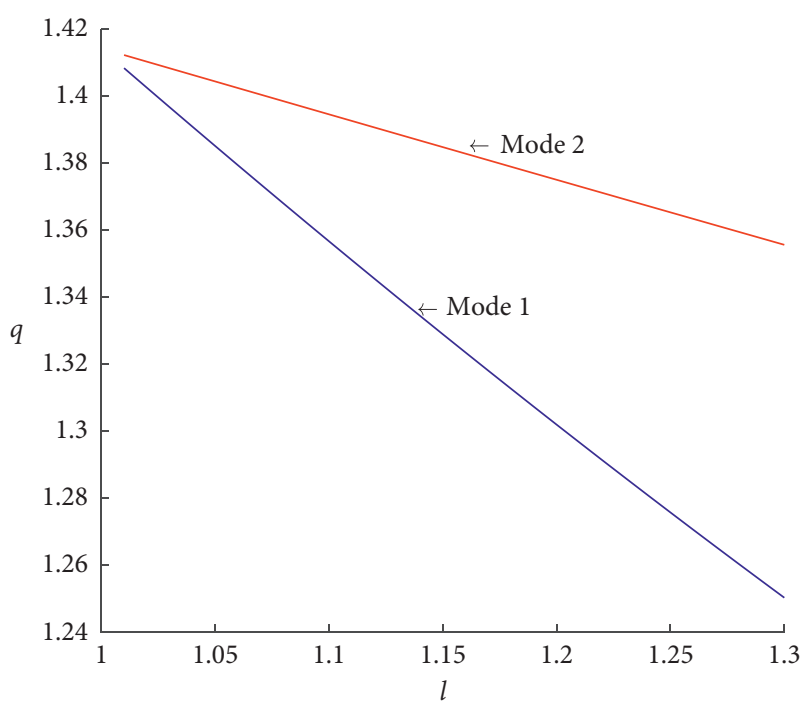

(b)

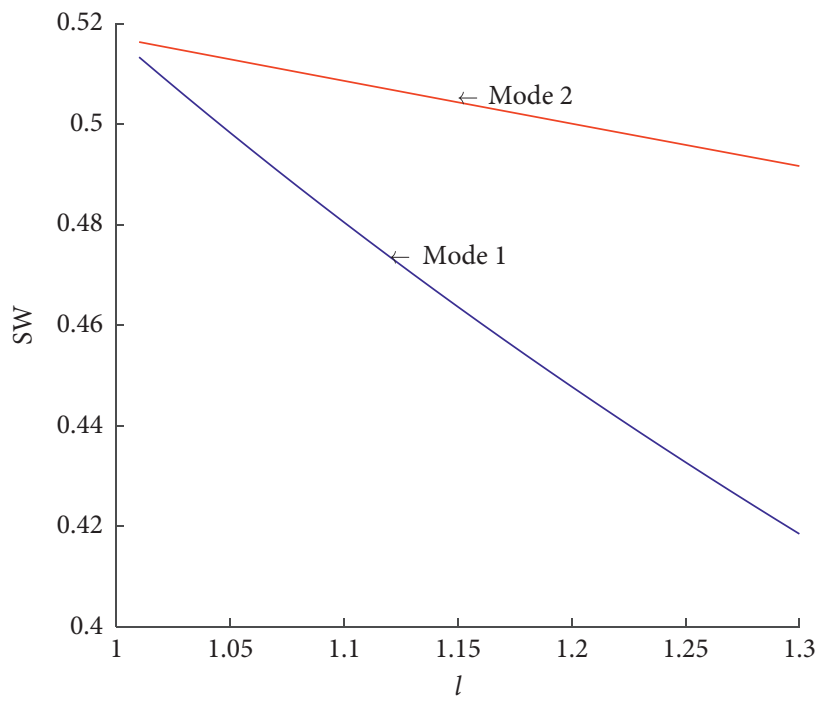

(d)

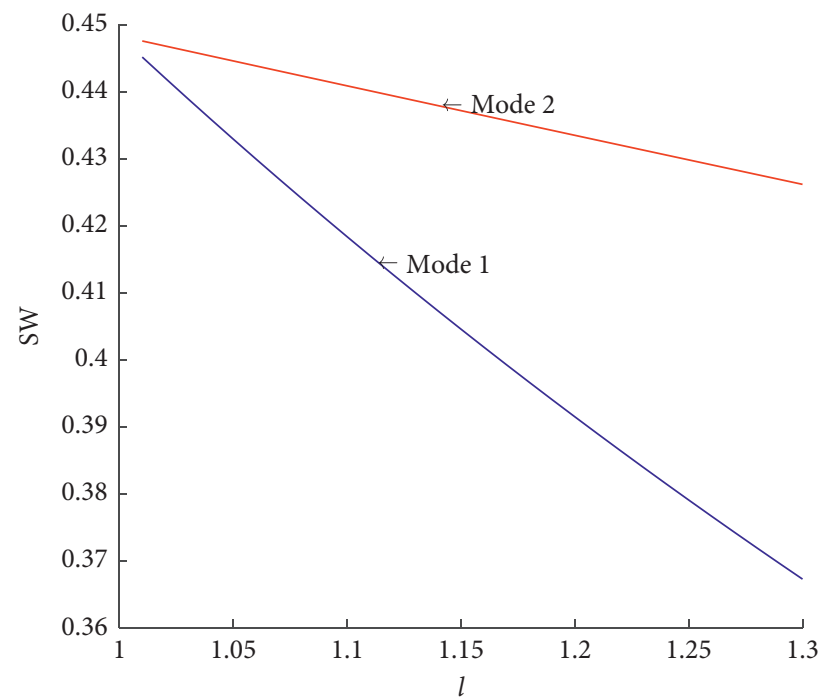

(e)

Figure 7: (a) The unit government subsidy as $l$ changes. (b) The safety investment as $l$ changes. (c) The government expenditure as $l$ changes. (d) The social welfare as $l$ changes when the government decides the subsidy. (e) The social welfare as $l$ changes when $S=0$. 
efforts. Figures 7(a) and 7(b) show that the per-unit subsidy and subsidy quantity both decrease with $l$, and thus Figure 7 (c) finally shows that the overall government expenditure will decrease with $l$. Figure $7(\mathrm{~d})$ shows that the demand-based payment can lead to a higher social welfare, and the social welfare decreases with $l$ when the government decides the subsidy. Figures $7(\mathrm{~d})$ and $7(\mathrm{e})$ also show that the demand-based payment is beneficial to the social welfare. Combing Sections 4.3 and 4.4, it is essential for food supply chain members to reduce the deterioration coefficient. As the deterioration coefficient is larger, it is necessary for the members to adopt demand-based payment to obtain higher profit or utility.

\section{Conclusion}

5.1. Summary of Findings. This paper studies the food supply chain where the food processor is the leader of the channel and processes the food which intrinsically attributes as nutritive, organoleptic, or other biochemical and biophysical characteristic values are unknown to the customers. Thus, the demand will depend on the customer's perception quality, which is uncertain for the food processor; however, the food processor can adopt safety investment to improve the customers' belief towards quality. The government as the leader in the three-stage game provides the food processor subsidies to raise the demand for safe food. Meanwhile, this paper compares the order quantity-based payment and the demand-based payment to discover the effects of payment methods on customer demands, the supplier's profit, and the food processor's utility. This paper also studies four cases based on different government subsidies and payment methods and determines the optimal wholesale price, marginal profit, safety investment, and government subsidies.

The main findings of this paper are as follows. (1) Suppliers can increase customer demands by sharing parts of the deterioration costs, but the demand-based payment is not always beneficial to supply chain members. (2) To encourage the risk-averse food processor to adopt safety investment, the subsidy increases with the food processor's risk-averse coefficient. The supplier's profit increases with the retailer's risk aversion indicator. (3) If the food processor does not adopt safety investment or the government endogenously decides the subsidy, the supplier's profit will increase with the retailer's risk aversion indicator. If the food processor adopts safety investment and the government does not decide subsidies, i.e., the subsidy is fixed at value, when the customer is relatively quality-sensitive, the supplier's profits will decrease with the food processor's risk aversion indicator.

5.2. Management Implications. In accordance with the conclusions of this research, the following suggestions are offered to the government and supply chain members. (1) Government subsidies can encourage the risk-averse processors to invest more in safety and improve the social welfare. When the cost coefficient of safety efforts is greater than a threshold, the government can maximize the social welfare by providing processing subsidies. (2) If the government does not provide subsidies, the processor should reduce risk aversion to improve utility. However, if the government decides the subsidy level aimed at social welfare maximization, the processor's utility will increase with the risk aversion indicator, but the government will increase expenditure. (3) It is necessary for the supplier to share parts of deterioration costs to increase the product demand; however, supply chain members may suffer profit loss.

5.3. Future Studies. Finally, the research detailed within this paper is summarized, along with its limitations, and possible directions for future research are also presented. In future research, one can incorporate the cooperation on safety investment into the model and examine the joint effects of supply chain members' cooperation and government subsidies on the demand for safe food. Since the supplier can improve the quality or safety of the food, we will consider the endogenous initial quality of food by taking the food supplier's safety efforts into account.

\section{Appendix}

\section{Proof of Proposition 1}

(i) $\left(\partial p_{11} / \partial k\right)=-\left(\beta^{2}(1-c l+s \beta) \sigma_{1}^{2} /\left(2+k(1+l) \quad \beta^{2}\right.\right.$ $\left.\left.\sigma_{1}^{2}\right)^{2}\right)<0, \quad\left(\partial U\left(\pi_{r 11}\right) / \partial k\right)=-\left(\beta^{2}(1-c l+s \beta)^{2} \sigma_{1}^{2} /\right.$ $\left.2\left(2+k(1+l) \beta^{2} \sigma_{1}^{2}\right)^{2}\right)<0, \quad\left(\partial p_{12} / \partial k\right)=-\left(\beta^{2}(1-c l+\right.$ $\left.s \beta) \sigma_{1}^{2} / 4\left(1+k \beta^{2} \sigma_{1}^{2}\right)^{2}\right)<0, \quad\left(\partial U\left(\pi_{r 12}\right) / \partial k\right)=-\left(\beta^{2}\right.$ $\left.(1-c l+s \beta)^{2} \sigma_{1}^{2} / 8\left(1+k \beta^{2} \sigma_{1}^{2}\right)^{2}\right)<0$.

(ii) $\left(\partial w_{11} / \partial k\right)=\left(\beta^{2}(1-c l+s \beta) \sigma_{1}^{2} /\left(2+k(1+l) \quad \beta^{2}\right.\right.$ $\left.\left.\sigma_{1}^{2}\right)^{2}\right)>0,\left(\partial E\left(\pi_{s 11}\right) / \partial k\right)=\left(2 l \beta^{2}(1-c l+s \beta)^{2} \sigma_{1}^{2}(1+\right.$ $\left.\left.k(1+l) \beta^{2} \sigma_{1}^{2}\right) /(1+l)\left(2+k(1+l) \beta^{2} \sigma_{1}^{2}\right)^{3}\right)>0,\left(\partial w_{12} /\right.$ $\partial k)=\left(\beta^{2}(1-c l+s \beta) \sigma_{1}^{2} / 4\left(1+k \beta^{2} \sigma_{1}^{2}\right)^{2}\right)>0, \quad(\partial E$ $\left.\left(\pi_{s 12}\right) / \partial k\right)=\left(\beta^{2}(1-c l+s \beta)^{2} \sigma_{1}^{2}\left(1+2 k \beta^{2} \sigma_{1}^{2}\right) / 8(1+\right.$ $\left.\left.k \beta^{2} \sigma_{1}^{2}\right)^{3}\right)>0$.

Proof of Proposition 2

$\left(U\left(\pi_{r 12}\right) / U\left(\pi_{r 11}\right)\right)=\left((1+l)\left(2+k(1+l) \beta^{2} \sigma_{1}^{2}\right) / 2\right.$ $\left.\left.2 k \beta^{2} \sigma_{1}^{2}\right)\right)>1, Q_{12}-Q_{11}=l(1-c l+s \beta)((l-1)(2+k$ $\left.(3+l) \beta^{2} \sigma_{1}^{2}+2 k^{2}(1+l) \beta^{4} \sigma_{1}^{4}\right) / 4\left(1+k \beta^{2} \sigma_{1}^{2}\right)(1+l)$ $\left.\left.k(1+l) \beta^{2} \sigma_{1}^{2}\right)\right)>0$.

\section{Proof of Proposition 3}

(i) $\left(\partial p_{21} / \partial k\right)=-\left((1+l) \beta^{2}\left(l \beta^{2}+(1+l) \lambda\right)\left(S_{21} \beta+(1-\right.\right.$ $\left.c l+s \beta) \quad \lambda) \sigma_{2}^{2} /\left(2(1+l) \lambda+\beta^{2}\left(k(1+l)^{2} \lambda \sigma_{2}^{2}-1\right)\right)^{2}\right)$ $<0,\left(\partial q_{21} / \partial k\right)=-\left((1+l)^{2} \beta^{3}\left(S_{21} \beta+(1-c l+s \beta) \lambda\right)\right.$ $\left.\sigma_{2}^{2} /\left(2(1+l) \lambda+\beta^{2}\left(k(1+l)^{2} \lambda \sigma_{2}^{2}-1\right)\right)^{2}\right)<0, \quad(\partial U$ $\left.\left(\pi_{r 21}\right) / \partial k\right)=-\left((1+l)^{2} \beta^{2}\left(S_{21} \beta+(1-c l+s \beta) \lambda\right)^{2}\right.$ $\left.\sigma_{2}^{2} / 2\left(2(1+l) \lambda+\beta^{2}\left(k(1+l)^{2} \lambda \sigma_{2}^{2}-1\right)\right)^{2}\right)<0,\left(\partial p_{22} /\right.$ $\partial k)=-\left(2 \beta^{2}\left(\beta^{2}+2 \lambda\right)\left(S_{22} \beta+(1-c l+s \beta) \lambda\right) \quad \sigma_{2}^{2} /\right.$ $\left.\left(4 \lambda+\beta^{2}\left(4 k \lambda \sigma_{2}^{2}-1\right)\right)^{2}\right)<0, \quad\left(\partial q_{22} / \partial k\right)=-\quad\left(4 \beta^{3}\right.$ $\left.\left(S_{22} \beta+(1-c l+s \beta) \lambda\right) \sigma_{2}^{2} /\left(4 \lambda+\beta^{2}\left(4 k \lambda \sigma_{2}^{2}-1\right)\right)^{2}\right)$ $<0,\left(\partial U\left(\pi_{r 22}\right) / \partial k\right)=-\left(2 \beta^{2}\left(S_{22} \beta+(1-c l+s \beta) \lambda\right)^{2}\right.$ $\left.\sigma_{2}^{2} /\left(4 \lambda+\beta^{2}\left(4 k \lambda \sigma_{2}^{2}-1\right)\right)^{2}\right)<0$. 
(ii) $\left(\partial w_{21} / \partial k\right)=\left((1+l) \beta^{2}\left(-\beta^{2}+(1+l) \lambda\right)\left(S_{21} \beta+(1-\right.\right.$ $\left.c l+s \beta) \lambda) \sigma_{2}^{2} /\left(2(1+l) \lambda+\beta^{2}\left(k(1+l)^{2} \lambda \sigma_{2}^{2}-1\right)\right)^{2}\right)$, if $\beta^{2}<(1+l) \lambda, \quad\left(\partial w_{21} / \partial k\right)>0$, else, $\quad\left(\partial w_{21} / \partial k\right)<0$. $\left(\partial E\left(\pi_{s 21}\right) / \partial k\right)=\left(2 l(1+l) \beta^{2}\left(-\beta^{2}+(1+l) \lambda\right)\left(S_{21}\right.\right.$ $\beta+(1-c l+s \beta) \lambda)^{2} \sigma_{2}^{2}\left(1+k(1+l) \beta^{2} \sigma_{2}^{2}\right) /(2 \quad(1+l)$ $\left.\left.\lambda+\beta^{2}\left(k(1+l)^{2} \lambda \sigma_{2}^{2}-1\right)\right)^{3}\right)$, if $\beta^{2}<(1+l) \lambda, \quad(\partial E$ $\left.\left(\pi_{s 21}\right) / \partial k\right)>0$, else, $\left(\partial E\left(\pi_{s 21}\right) / \partial k\right)<0$. $\left(\partial D_{21} / \partial k\right)=$ $-\left((1+l) \beta^{2}\left(\beta^{2}-(1+l) \lambda\right)\left(S_{21} \beta+(1-c l+s \beta) \lambda\right)\right.$ $\left.\sigma_{2}^{2} /\left(2(1+l) \lambda+\beta^{2}\left(-1+k \quad(1+l)^{2} \lambda \sigma_{2}^{2}\right)\right)^{2}\right), \quad$ if $\beta^{2}<(1+l) \lambda,\left(\partial D_{21} / \partial k\right)>0$, else, $\left(\partial D_{21} / \partial k\right)<0$.

(iii) $\left(\partial w_{22} / \partial k\right)=-\left(2 \beta^{2}\left(\beta^{2}-2 \lambda\right) \quad\left(S_{22} \beta+(1-\right.\right.$ $\left.c l+s \beta) \lambda) \sigma_{2}^{2} /\left(4 \lambda+\beta^{2}\left(-1+4 k \lambda \sigma_{2}^{2}\right)\right)^{2}\right), \quad$ if $\quad \beta^{2}<2 \lambda$, $\left(\partial w_{22} / \partial k\right)>0$, else, $\left(\partial w_{22} / \partial k\right)<0$. $\left(\partial E\left(\pi_{s 22}\right) / \partial k\right)=$ $-\left(4 \beta^{2}\left(\beta^{2}-2 \lambda\right)\left(S_{42} \beta+(1-c l+s \beta) \lambda\right)^{2} \sigma_{2}^{2}\left(1+2 k \beta^{2}\right.\right.$ $\left.\left.\sigma_{2}^{2}\right) /\left(4 \lambda+\beta^{2}\left(-1+4 k \lambda \sigma_{2}^{2}\right)\right)^{3}\right)$, if $\beta^{2}<2 \lambda, \quad\left(\partial E\left(\pi_{s 22}\right)\right.$ $/ \partial k)>0$, else, $\quad\left(\partial E\left(\pi_{s 22}\right) / \partial k\right)<0 . \quad\left(\partial D_{22} / \partial k\right)=-$ $\left(2 l \beta^{2}\left(\beta^{2}-2 \lambda\right) \quad\left(S_{22} \beta+(1-c l+s \beta) \lambda\right) \sigma_{2}^{2} /\left(4 \lambda+\beta^{2}\right.\right.$ $\left.\left.\left(-1+4 k \lambda \sigma_{2}^{2}\right)\right)^{2}\right)$, if $\beta^{2}<2 \lambda, \quad \partial D_{22} / \partial k>0$, else, $\partial D_{22} / \partial k<0$.

Proof of Proposition 4

$q_{22}-q_{21}=((1-l) \beta(-\lambda+c l \lambda-\beta(S+s \lambda))(2+k(3+l)$ $\left.\beta^{2} \sigma_{2}^{2}\right) /\left(4 \lambda+\beta^{2}\left(-1+4 k \lambda \sigma_{2}^{2}\right)\right)\left(2(1+l) \lambda+\beta^{2}\left(-1+k(1+l)^{2}\right.\right.$ $\left.\left.\lambda \sigma_{2}^{2}\right)\right)>0, \quad Q_{22}-Q_{21}=l(S \beta+\lambda-c l \lambda+s \beta \lambda)((l-1)$ $\left(2 \lambda+k \beta^{2} \sigma_{2}^{2}\left(\beta^{2}+(3+l) \lambda+2 k(1+l) \beta^{2} \lambda \sigma_{2}^{2}\right)\right) /\left(4 \lambda+\beta^{2}(-1+\right.$ $\left.\left.\left.4 k \lambda \sigma_{2}^{2}\right)\right)\left(2(1+l) \lambda+\beta^{2}\left(-1+k(1+l)^{2} \lambda \sigma_{2}^{2}\right)\right)\right)>0, \quad U\left(\pi_{r 22}\right)-$ $U\left(\pi_{r 21}\right)=(l-1)(S \beta+(1-c l+s \beta) \lambda)^{2}\left(2+k(3+l) \beta^{2} \sigma_{2}^{2}\right) /$ $2\left(4 \lambda+\beta^{2}\left(-1+4 k \lambda \sigma_{2}^{2}\right)\right)\left(2(1+l) \lambda+\beta^{2}\left(-1+k(1+l)^{2} \lambda \sigma_{2}^{2}\right)\right)$ $>0$.

\section{Proof of Proposition 5}

(i) $\mathrm{SW}_{21}=\left(1 / 2\left(2(1+l) \lambda+\beta^{2}\left(-1+k(1+l)^{2} \quad \lambda \sigma_{2}^{2}\right)\right)^{2}\right)$ $\left(\left((-1+c l-s \beta) \lambda-\beta S_{21}\right)^{2} \quad\left(1+k(1+l) \beta^{2} \sigma_{2}^{2}\right)^{2}+\right.$ $2\left(((-1+c l-s \beta)) \lambda-\beta S_{21}\right)^{2}\left(1+k(1+l) \beta^{2} \sigma_{2}^{2}\right) \quad(1+$ $\left.2 l+k l(1+l) \beta^{2} \sigma_{2}^{2}\right)-\lambda\left(\beta(-1+c l-s \beta)-(1+l) S_{21}\right.$ $\left.\left.\left(2+k \quad(1+l) \beta^{2} \sigma_{2}^{2}\right)\right)^{2}\right),\left(\partial \mathrm{SW}_{21} / \partial S_{21}\right)=(1 / 2(2(1+$ $\left.\left.l) \lambda+\beta^{2}\left(-1+k(1+l)^{2} \lambda \sigma_{2}^{2}\right)\right)^{2}\right)(2 \beta(1-c l+s \beta) \lambda(1+$ $\left.2 l+k(1+l) \beta^{2} \sigma_{2}^{2}\left(3+5 l+k(1+l)(1+2 l) \beta^{2} \sigma_{2}^{2}\right)\right)+$ $2 S_{21}\left((3+4 l) \beta^{2}-4(1+l)^{2} \lambda+k(1+l) \beta^{2} \sigma_{2}^{2}((4+6 l)\right.$ $\beta^{2}-4(1+l)^{2} \lambda-k(1+l) \beta^{2}\left(-(1+2 l) \beta^{2}+(1+l)^{2} \lambda\right)$ $\left.\left.\sigma_{2}^{2}\right)\right)$ ),

$\left(\partial^{2} S W_{21} / \partial S_{21}^{2}\right)=\left((3+4 l) \beta^{2}-4(1+l)^{2} \lambda+k(1+l)\right.$ $\beta^{2} \sigma_{2}^{2}\left((4+6 l) \beta^{2}-4(1+l)^{2} \lambda-k(1+l) \beta^{2} \quad(-(1+2 l)\right.$ $\left.\left.\beta^{2}+\quad(1+l)^{2} \lambda\right) \sigma_{2}^{2}\right) /\left(2(1+l) \lambda+\beta^{2}\left(-1+k(1+l)^{2}\right.\right.$ $\left.\left.\left.\lambda \sigma_{2}^{2}\right)\right)^{2}\right)$, if $\lambda>\left(\beta^{2}\left(3+4 l+k(1+l) \beta^{2} \sigma_{2}^{2}(4+6 l+k\right.\right.$ $\left.\left.\left.(1+l)(1+2 l) \quad \beta^{2} \sigma_{2}^{2}\right)\right) /(1+l)^{2}\left(2+k(1+l) \beta^{2} \sigma_{2}^{2}\right)^{2}\right)$, $\left(\partial^{2} S W_{21} / \partial S_{21}^{2}\right)<0$. Therefore, when $\lambda>\beta^{2}(3+4 l+$ $\left.k(1+l) \beta^{2} \sigma_{2}^{2}\left(4+6 l+k(1+l)(1+2 l) \beta^{2} \sigma_{2}^{2}\right)\right) /(1+l)^{2}$ $\left(2+k(1+l) \beta^{2} \sigma_{2}^{2}\right)^{2}$, the social welfare function is concave.

(ii) Since the proof here is similar to that in (i), we omit them.

\section{Proof of Proposition 6}

(i) $\partial S_{21} / \partial k=(1+l)^{2} \beta^{3}(1-c l+s \beta) \lambda \sigma_{2}^{2} f_{1}(k) /((3+4 l)$ $\beta^{2}-4(1+l)^{2} \lambda+k(1+l) \beta^{2} \sigma_{2}^{2}\left((4+6 l) \beta^{2}-4 \quad(1+\right.$ $\left.\left.l)^{2} \lambda-k(1+l) \beta^{2} \quad\left(-(1+2 l) \beta^{2}+(1+l)^{2} \lambda\right) \sigma_{2}^{2}\right)^{2}\right)$, $f_{1}(k)=-\left((5+8 l) \beta^{2}+4(1+l) \quad(2+3 l) \lambda+k(1+\right.$ l) $\beta^{2} \quad \sigma_{2}^{2}\left(\left(2(1+2 l)\left(-2 \beta^{2}+3(1+l) \lambda\right)\right)+k(1+\right.$ $\left.l) \beta^{2}\left(\left(-(1+2 l) \quad \beta^{2}+\lambda+l(4+3 l) \lambda\right) \sigma_{2}^{2}\right)\right) ; \quad$ since $\lambda>\left(\beta^{2}\left(3+4 l+k(1+l) \quad \beta^{2} \sigma_{2}^{2}(4+6 l+k(1+l)\right.\right.$ $\left.\left.\left.(1+2 l) \beta^{2} \sigma_{2}^{2}\right)\right) /(1+l)^{2}\left(2+k(1+l) \beta^{2} \sigma_{2}^{2}\right)^{2}\right)$, we get $f_{1}(k)>2 \beta^{2} \quad\left(2 l+k \beta^{2} \sigma_{2}^{2}(1+5 l(1+l)+k l(1+l)\right.$ $\left.\left.(1+2 l) \beta^{2} \sigma_{2}^{2}\right)+1-\left(1 / 2+k(1+l) \beta^{2} \sigma_{2}^{2}\right) / 1+l\right)>0$, and thus we get $\partial S_{21} / \partial k>0$.

$\partial S_{22} / \partial k=\left(4 \beta^{3}(1-c l+s \beta) \quad \lambda \sigma_{2}^{2} f_{2}(k) /\left(7 \beta^{2}-16\right.\right.$ $\left.\left.\lambda+4 k \beta^{2} \sigma_{2}^{2}\left(5 \beta^{2}-8 \lambda+k \beta^{2}\left(3 \beta^{2}-4 \lambda\right) \sigma_{2}^{2}\right)\right)^{2}\right), \quad f_{2}$ $(k)=-13 \beta^{2}+40 \lambda-4 k \beta^{2} \sigma_{2}^{2}\left(6\left(\beta^{2}-3 \lambda\right)+k \beta^{2}\left(3 \beta^{2}\right.\right.$ $\left.-8 \lambda) \sigma_{2}^{2}\right) ;$ since $\lambda>\left(\beta^{2}\left(1+2 k \beta^{2} \sigma_{2}^{2}\right)\left(7+6 k \beta^{2} \sigma_{2}^{2}\right)\right.$ $\left./ 16\left(1+k \beta^{2} \sigma_{2}^{2}\right)^{2}\right)$, we get $f_{2}(k)>(1 / 2) \beta^{2} \quad(10-$ $\left.\left(1 / 1+k \beta^{2} \sigma_{2}^{2}\right)+4 k \beta^{2} \sigma_{2}^{2}\left(11+6 k \beta^{2} \sigma_{2}^{2}\right)\right)>0$, and thus we get $\left(\partial S_{22} / \partial k\right)>0$.

(ii) $q_{21}=-1 /-(3+4 l) \beta^{2}+4(1+l)^{2} \lambda+k(1+l) \quad \beta^{2}$ $\sigma_{2}^{2}\left(-2(2+3 l) \beta^{2}+4(1+l)^{2} \lambda+k(1+l) \quad \beta^{2}(-(1+\right.$ $\left.\left.2 l) \beta^{2}+(1+l)^{2} \lambda\right) \sigma_{2}^{2}\right) 1 /((3+4 l) \quad(-1+c l) \beta-4(1+$ $l)^{2} s \lambda+k(1+l) \beta^{2} \quad \sigma_{2}^{2}(2(2+3 l)(-1+c l)$ $\beta-4(1+l)^{2} \quad s \lambda+k(1+l) \beta^{2}((1+2 l)(-1+c l) \beta-$ $\left.\left.(1+l)^{2} s \lambda\right) \sigma_{2}^{2}\right)$

$q_{22}=\left(7(-1+c l) \beta-16 s \lambda+4 k \beta^{2} \sigma_{2}^{2} \quad(5(-1+c l) \beta-\right.$ $\left.8 s \lambda+k \beta^{2} \quad(3(-1+c l) \beta-4 s \lambda) \sigma_{2}^{2}\right) / 7 \beta^{2}-16 \lambda+4 k \beta^{2}$ $\left.\sigma_{2}^{2}\left(5 \beta^{2}-8 \lambda+k \beta^{2}\left(3 \beta^{2}-4 \lambda\right) \sigma_{2}^{2}\right)\right)$.

$\partial q_{21} / \partial k=2(1+l)^{3} \beta^{3} \quad(1-c l+s \beta) \lambda \sigma_{2}^{2}(2+4 l+k$ $\left.(1+l) \beta^{2} \sigma_{2}^{2}\left(1+4 l+k l(1+l) \beta^{2} \sigma_{2}^{2}\right)\right) / \quad\left(-(3+4 l) \beta^{2}\right.$ $+4(1+l)^{2} \lambda+k(1+l) \beta^{2} \sigma_{2}^{2}\left(-2(2+3 l) \beta^{2}+4(1+l)^{2}\right.$ $\left.\left.\lambda+k(1+l) \beta^{2}\left(-(1+2 l) \beta^{2}+(1+l)^{2} \lambda\right) \sigma_{2}^{2}\right)\right)^{2}>0$,

$\partial q_{22} / \partial k=32 \beta^{3} \quad(1-c l+s \beta) \lambda \sigma_{2}^{2}\left(1+k \beta^{2} \sigma_{2}^{2}\right)(3+$ $\left.2 k \beta^{2} \sigma_{2}^{2}\right) /\left(7 \beta^{2}-16 \lambda+4 k \beta^{2} \sigma_{2}^{2}\left(5 \beta^{2}-8 \lambda+k \beta^{2}\left(3 \beta^{2}-\right.\right.\right.$

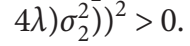

(iii) $\pi_{s 21}=-l(1+l)(-1+c l-s \beta) \lambda \quad\left(1+k(1+l) \beta^{2} \sigma_{2}^{2}\right)$ $\left(2+k(1+l) \beta^{2} \sigma_{2}^{2}\right) /-(3+4 l) \beta^{2}+4(1+l)^{2} \lambda+k(1$ $+l) \beta^{2} \sigma_{2}^{2}\left(-2(2+3 l) \beta^{2}+4(1+l)^{2} \lambda+k \quad(1+l) \beta^{2}\right.$ $\left.\left(-(1+2 l) \beta^{2}+(1+l)^{2} \lambda\right) \sigma_{2}^{2}\right), \partial \pi_{s 21} / \partial k=l(1+l)^{2} \beta^{2}$ $(1-c l+s \beta) \lambda \sigma_{2}^{2} f_{1}(\lambda) /\left((3+4 l) \beta^{2}-4 \quad(1+l)^{2} \lambda+\right.$ $k(1+l) \beta^{2} \sigma_{2}^{2}\left((4+6 l) \beta^{2}-4(1+l)^{2} \lambda-k(1+l) \quad \beta^{2}\right.$ $\left.\left.\left(-(1+2 l) \beta^{2}+(1+l)^{2} \lambda\right) \sigma_{2}^{2}\right)\right)^{2}, f_{1}(\lambda)=-\beta^{2}+4(1+$ $l)^{2} \lambda+k(1+l) \beta^{2} \sigma_{2}^{2} \quad\left(-2 \beta^{2}+4(1+l)^{2} \lambda+k(1+l) \beta^{2}\right.$ $\left.\left(-\beta^{2}+(1+l)^{2} \lambda\right) \sigma_{2}^{2}\right), \quad \lambda>\beta^{2}\left(3+4 l+k(1+l) \beta^{2} \sigma_{2}^{2}\right.$ $\left.\left(4+6 l+k(1+l) \quad(1+2 l) \beta^{2} \sigma_{2}^{2}\right)\right) /(1+l)^{2}(2+k$ $\left.(1+l) \beta^{2} \sigma_{2}^{2}\right)^{2}, f_{1}(\lambda)>2 \quad \beta^{2}\left(1+2 l+k(1+l) \beta^{2} \sigma_{2}^{2}\right.$ $\left.\left(1+3 l+k l(1+l) \beta^{2} \sigma_{2}^{2}\right)\right)>0, \partial \pi_{s 21} / \partial k>0$.

$\pi_{s 22}=16(1-c l+s \beta)^{2} \lambda^{2}\left(1+k \beta^{2} \sigma_{2}^{2}\right)^{2}\left(1+2 k \beta^{2} \sigma_{2}^{2}\right)^{2}$

$/\left(7 \beta^{2}-16 \lambda+4 k \beta^{2} \sigma_{2}^{2}\left(5 \beta^{2}-8 \lambda+k \beta^{2}\left(3 \beta^{2}-4 \lambda\right)\right.\right.$ $\left.\left.\sigma_{2}^{2}\right)\right)^{2}, \partial \pi_{s 22} / \partial k=32 \beta^{2}(1-c l+s \beta)^{2} \lambda^{2} \sigma_{2}^{2} \quad\left(1+k \beta^{2}\right.$ $\left.\sigma_{2}^{2}\right) \quad\left(1+2 k \beta^{2} \sigma_{2}^{2}\right) f_{2}(\lambda) /\left(7 \beta^{2}-16 \lambda+4 k \beta^{2} \sigma_{2}^{2}\left(5 \beta^{2}\right.\right.$ $\left.\left.-8 \lambda+k \beta^{2}\left(3 \beta^{2}-4 \lambda\right) \sigma_{2}^{2}\right)\right)^{3}, f_{2}(\lambda)=\beta^{2}-16 \lambda+4 k \beta^{2}$ $\sigma_{2}^{2}\left(\beta^{2}-8 \lambda+k \beta^{2}\left(\beta^{2}-4 \lambda\right) \sigma_{2}^{2}\right), \quad \lambda>\beta^{2}\left(1+2 k \beta^{2} \sigma_{2}^{2}\right)$ $\left(7+6 k \beta^{2} \sigma_{2}^{2}\right) / 16\left(1+k \beta^{2} \sigma_{2}^{2}\right)^{2}, f_{2}(\lambda)<-2 \beta^{2}(3+4 k$ $\left.\beta^{2} \sigma_{2}^{2}\left(2+k \beta^{2} \sigma_{2}^{2}\right)\right)<0, \partial \pi_{s 22} / \partial k>0$. 


$$
\text { (iv) } \begin{array}{rr}
Q_{21}=(1+l)(1-c l+s \beta) \lambda\left(2+k(1+l) \quad \beta^{2} \sigma_{2}^{2}(3+\right. \\
\left.\left.k(1+l) \quad \beta^{2} \sigma_{2}^{2}\right)\right) / f_{3}(\lambda), \quad f_{3}(\lambda)=-(3+4 l) \beta^{2}+ \\
4(1+l)^{2} \lambda+k(1+l) \beta^{2} \sigma_{2}^{2}\left(-2(2+3 l) \beta^{2}+4 \quad(1+l)^{2}\right. \\
\left.\lambda+k(1+l) \beta^{2}\left(-(1+2 l) \beta^{2}+(1+l)^{2} \lambda\right) \sigma_{2}^{2}\right), \quad Q_{22}= \\
4(-1+c l-s \beta) \lambda\left(1+k \beta^{2} \quad \sigma_{2}^{2}\right)\left(1+2 k \beta^{2} \sigma_{2}^{2}\right) / 7 \beta^{2}- \\
16 \lambda+4 k \beta^{2} \sigma_{2}^{2}\left(5 \beta^{2}-8 \lambda+k \beta^{2}\left(3 \beta^{2}-4 \lambda\right) \sigma_{2}^{2}\right), \\
Q_{22}-Q_{21}=(1-c l+s \beta) \lambda(l-1) /\left(7 \beta^{2}-16 \lambda+4 k\right. \\
\left.\beta^{2} \sigma_{2}^{2}\left(5 \beta^{2}-8 \lambda+k \beta^{2}\left(3 \beta^{2}-4 \lambda\right) \sigma_{2}^{2}\right)\right)\left(-f_{3} \quad(\lambda)\right)(16 \\
(1+l) \lambda-2 \beta^{2}+k \beta^{2} \sigma_{2}^{2}\left((3+l)\left(-3 \beta^{2}+16(1+l) \lambda\right)+\right. \\
k \beta_{2}^{2} \sigma_{2}^{2}\left((15+l(12+l))\left(-\beta^{2}+4(1+l) \lambda\right)+4 k\right. \\
(1+l) \beta^{2} \sigma_{2}^{2}\left((3+l)\left(-\beta^{2}+3(1+l) \lambda\right)+k(1+l) \beta^{2}(-\right. \\
\left.\left.\left.\left.\beta^{2}+2(1+l) \lambda\right) \sigma_{2}^{2}\right)\right)\right)>0 .
\end{array}
$$

\section{Data Availability}

No data were used to support this study.

\section{Conflicts of Interest}

The authors declare that they have no conflicts of interest.

\section{Acknowledgments}

This study was supported by the National Natural Science Foundation of China (nos. 71771053 and 71371003), the Key Research and Development Plan (Modern Agriculture) of Jiangsu Province (no. BE2018385), and the Natural Science Foundation of Jiangsu Province (no. BK20201144).

\section{References}

[1] I. E. Nielsen, S. Majumder, S. S. Sana, and S. Saha, "Comparative analysis of government incentives and game structures on single and two-period green supply chain," Journal of Cleaner Production, vol. 235, pp. 1371-1398, 2019.

[2] S. Saha, S. Majumder, and I. E. Nielsen, "Is it a strategic move to subsidized consumers instead of the manufacturer?" IEEE Access, vol. 7, pp. 169807-169824, 2019.

[3] I. E. Nielsen, S. Majumder, and S. Saha, "Game-theoretic analysis to examine how government subsidy policies affect a closed-loop supply chain decision," Applied Sciences, vol. 10, 2020.

[4] Y. Qin, J. Wang, and C. Wei, "Joint pricing and inventory control for fresh produce and foods with quality and physical quantity deteriorating simultaneously," International Journal of Production Economics, vol. 152, pp. 42-48, 2014.

[5] Y. Hung, W. Verbeke, and T. M. de Kok, "Stakeholder and consumer reactions towards innovative processed meat products: insights from a qualitative study about nitrite reduction and phytochemical addition," Food Control, vol. 60, pp. 690-698, 2016.

[6] P. Y. Lee, K. Lusk, M. Mirosa, and I. Oey, "Effect of information on Chinese consumers' perceptions and purchase intention for beverages processed by high pressure processing, pulsed-electric field and heat treatment," Food Quality and Preference, vol. 40, pp. 16-23, 2015.

[7] M. A. P. M. V. Asseldonk, L. Malaguti, M. L. H. Breukers, and H. J. van der FELS-KLERX, "Understanding preferences for interventions to reduce microbiological contamination in Dutch vegetable production," Journal of Food Protection, vol. 81, no. 6, pp. 892-897, 2018.
[8] H.-W. Huang, S.-J. Wu, J.-K. Lu, Y.-T. Shyu, and C.-Y. Wang, "Current status and future trends of high-pressure processing in food industry," Food Control, vol. 72, pp. 1-8, 2017.

[9] N. N. Mohand, A. Hammoudi, M. S. Radjef et al., "How do food safety regulations influence market price? A theoretical analysis," British Food Journal, vol. 119, no. 8, pp. 1687-1704, 2017.

[10] V. Hoffmann, C. Moser, and A. Saak, "Food safety in low and middle-income countries: The evidence through an economic lens," World Development, vol. 12, 2019.

[11] Q. Zheng and T. Fan, "Design of incentive contract for fresh agricultural products supply chain considering risk preference," Journal of Industrial Engineering and Engineering Management, vol. 32, no. 2, pp. 171-178, 2018.

[12] F. Lin, "Dynamic pricing, quality investment, and replenishment model for perishable items," International Transactions in Operational Research, vol. 26, no. 4, pp. 1558-1575, 2019.

[13] I. Moon, Y. J. Jeong, and S. Saha, "Investment and coordination decisions in a supply chain of fresh agricultural products," Operational Research, vol. 20, no. 4, pp. 2307-2331, 2020.

[14] M. Wang and L. Zhao, "Cold chain investment and pricing decisions in a fresh food supply chain," International Transactions in Operational Research, vol. 28, no. 2, pp. 1074-1097, 2021.

[15] M. S. Vodenicharova, "Supply chain study in food industry in Bulgaria," International Journal of Retail \& Distribution Management, vol. 48, no. 9, pp. 921-938, 2020.

[16] J. C. P. Mesa and E. G. Gomez, "Collaborative firms managing perishable products in a complex supply network: an empirical analysis of performance," Supply Chain Management: An International Journal, vol. 20, no. 2, pp. 128-138, 2015.

[17] J. Labrecque, B. Dulude, and S. Charlebois, "Sustainability and strategic advantages using supply chain-based determinants in pork production," British Food Journal, vol. 117, no. 11, pp. 2630-2648, 2015.

[18] P. T. Rucabado and P. M. Cuellar, "Short food supply chains for local food: a difficult path," Renewable Agriculture and Food Systems, vol. 35, no. 2, pp. 182-191, 2020.

[19] J. Chen and B. Dan, "Fresh agricultural product supply chain coordination under the physical loss-controlling," Systems Engineering-Theory \& Practice, vol. 29, no. 3, pp. 54-62, 2009.

[20] H. Huang, Y. He, and D. Li, "Pricing and inventory decisions in the food supply chain with production disruption and controllable deterioration," Journal of Cleaner Production, vol. 180, pp. 280-296, 2018.

[21] J. He, Y. Lei, X. Fu et al., "How Can manufacturers promote green innovation in food supply chain? cost sharing strategy for supplier motivation," Frontiers in Psychology, vol. 11, 2020.

[22] A. Singh, N. Shukla, and N. Mishra, "Social media data analytics to improve supply chain management in food industries," Transportation Research Part E: Logistics and Transportation Review, vol. 114, pp. 398-415, 2018.

[23] J. Qian, B. Dai, B. Wang et al., "Traceability in food processing: problems, methods, and performance evaluations-a review," Critical Reviews in Food Science and Nutrition, 2020.

[24] A. C. Kappelman and A. K. Sinha, "Optimal control in dynamic food supply chains using big data," Computers \& Operations Research, vol. 126, 2021.

[25] N. Mishra, A. Singh, N. P. Rana et al., "Interpretive structural modelling and fuzzy MICMAC approaches for customer centric beef supply chain: application of a big data technique," 
Production Planning \& Control, vol. 28, no. 11-12, pp. 945963, 2017.

[26] V. A. Nardi, R. Teixeira, W. J. Ladeira, and F. D. Santini, “A meta-analytic review of food safety risk perception," Food Control, vol. 112, 2020.

[27] J. Hou, L. Wu, and B. Hou, "Risk attitude, contract arrangements and enforcement in food safety governance: a China's agri-food supply chain scenario," International Journal of Environmental Research and Public Health, vol. 17, no. 8, p. 2733, 2020.

[28] T. Schoenherr, R. Narasimhan, and P. Bandyopadhyay, "The assurance of food safety in supply chains via relational networking," International Journal of Operations \& Production Management, vol. 35, no. 12, pp. 1662-1687, 2015.

[29] C.-H. Chiu, T.-M. Choi, G. Hao, and X. Li, "Innovative menu of contracts for coordinating a supply chain with multiple mean-variance retailers," European Journal of Operational Research, vol. 246, no. 3, pp. 815-826, 2015.

[30] Q. Cui, C.-H. Chiu, X. Dai, and Z. Li, "Store brand introduction in a two-echelon logistics system with a risk-averse retailer," Transportation Research Part E: Logistics and Transportation Review, vol. 90, pp. 69-89, 2016.

[31] C.-H. Chiu, T.-M. Choi, X. Dai, B. Shen, and J.-H. Zheng, "Optimal advertising budget allocation in luxury fashion markets with social influences: a mean-variance analysisfluences: a mean-variance analysis," Production and Operations Management, vol. 27, no. 8, pp. 1611-1629, 2018.

[32] S. Zhao and Q. Zhu, "A risk-averse marketing strategy and its effect on coordination activities in a remanufacturing supply chain under market fluctuation," Journal of Cleaner Production, vol. 171, pp. 1290-1299, 2018.

[33] S. Deng, W. Li, and T. Wang, "Subsidizing mass adoption of electric vehicles with a risk-averse manufacturer," Physica A: Statistical Mechanics and Its Applications, vol. 547, 2020.

[34] C.-H. Chiu and T.-M. Choi, "Supply chain risk analysis with mean-variance models: a technical review," Annals of Operations Research, vol. 240, no. 2, pp. 489-507, 2016.

[35] T.-M. Choi, X. Wen, X. Sun, and S.-H. Chung, "The meanvariance approach for global supply chain risk analysis with air logistics in the blockchain technology era," Transportation Research Part E: Logistics and Transportation Review, vol. 127, pp. 178-191, 2019.

[36] X. Wen and T. Siqin, "How do product quality uncertainties affect the sharing economy platforms with risk considerations? A mean-variance analysis," International Journal of Production Economics, vol. 224, 2020.

[37] B. He, X. Gan, and K. Yuan, "Entry of online presale of fresh produce: a competitive analysis," European Journal of Operational Research, vol. 272, no. 1, pp. 339-351, 2019.

[38] X. Cai, J. Chen, Y. Xiao et al., "Optimization and coordination of fresh product supply chains with freshness-keeping effort," Production and Operations Management, vol. 19, no. 3, pp. 261-278, 2010.

[39] Y. Yu and T. Xiao, "Pricing and cold-chain service level decisions in a fresh agri-products supply chain with logistics outsourcing," Computers \& Industrial Engineering, vol. 111, pp. 56-66, 2017.

[40] L. Yang, R. Tang, and K. Chen, "Call, put and bidirectional option contracts in agricultural supply chains with sales effort," Applied Mathematical Modelling, vol. 47, pp. 1-16, 2017.

[41] C. Wang and X. Chen, "Option pricing and coordination in the fresh produce supply chain with portfolio contracts," Annals of Operations Research, vol. 248, no. 1-2, pp. 471-491, 2017.
[42] M. Wang, L. Zhao, and M. Herty, "Modelling carbon trading and refrigerated logistics services within a fresh food supply chain under carbon cap-and-trade regulation," International Journal of Production Research, vol. 56, no. 12, pp. 4207-4225, 2018.

[43] J. Wu, J. Li, S. Wang, and T. Cheng, "Mean-variance analysis of the newsvendor model with stockout cost 2 ," Omega, vol. 37, no. 3, pp. 724-730, 2009.

[44] W. Xing, S. Wang, and L. Liu, "Optimal ordering and pricing strategies in the presence of a B2B spot market," European Journal of Operational Research, vol. 221, no. 1, pp. 87-98, 2012.

[45] D. Krass, T. Nedorezov, and A. Ovchinnikov, "Environmental taxes and the choice of green technology," Production and Operations Management, vol. 22, no. 5, pp. 1035-1055, 2013.

[46] S. Mohammadreza and R.-B. Morteza, "A game theoretic approach for pricing, greening, and social welfare policies in a supply chain with government intervention," Journal of Cleaner Production, vol. 196, pp. 1443-1458, 2018. 